\title{
GÊNESE DE SOLOS DERIVADOS DE ROCHAS ULTRAMÁFICAS SERPENTINIZADAS NO SUDOESTE DE MINAS GERAIS ${ }^{(1)}$
}

\author{
Pablo Vidal-Torrado ${ }^{(2)}$, Felipe Macias $^{(3)}$, Rosa Calvo $^{(3)}$, \\ Sebastião Gomes de Carvalho ${ }^{(4)} \&$ Alexandre \\ Christófaro Silva ${ }^{(5)}$
}

\begin{abstract}
RESUMO
Os solos derivados de rochas serpentinizadas ou serpentinitos constituem um grupo especial de solos em toda superfície terrestre. De caráter ultramáfico, ou seja, rochas com mais de $70 \%$ de minerais máficos (ferromagnesianos), os serpentinitos apresentam uma mineralogia pobre em sílica e escassa em $\mathrm{Al}$, sendo, no entanto, muito enriquecida em Mg. São poucos os estudos sobre a morfologia, mineralogia, gênese e classificação dos solos desenvolvidos de tais rochas. Em ambiente tropical úmido no sudoeste de Minas Gerais, na zona do greenstone belt do Morro de Ferro, em superfícies geomórficas jovens, três perfis de solos representativos dessa paisagem sobre rochas serpentinizadas foram caracterizados por meio de descrições macro e micromorfológicas, análises granulométricas, químicas e por mineralogia de raios $X$ das frações argila e silte. Complementarmente, para acompanhamento da alteração geoquímica dos horizontes do solo, foram feitas microanálises das seções delgadas por EDRX. Os solos foram classificados como Chernossolo Háplico Férrico típico, Cambissolo Háplico eutroférrico léptico e Neossolo Regolítico eutrófico típico e, embora situados num clima que favorece o rápido intemperismo, do ponto de vista morfológico e mineralógico, mostraram-se similares aos solos derivados de rochas
\end{abstract}

(1) Parte da Tese de Livre Docência do primeiro autor. Trabalho financiado pela FAPESP e pela Universidade de Santiago de Compostela. Recebido para publicação em dezembro de 2005 e aprovado em março de 2006.

(2) Professor do Departamento de Ciência do Solo da Escola Superior de Agricultura "Luiz de Queiroz", Universidade de São Paulo - ESALQ/USP. Av. Pádua Dias 11, Caixa Postal 09, CEP 13418-900 Piracicaba (SP). Bolsista do CNPq. E-mail: pablo@esalq.usp.br

(3) Professor do Departamento de Edafoloxia, Facultad de Bioloxia, Universidad de Santiago de Compostela. CP 15706, Santiago de Compostela, Espanha. E-mail: edfmac@usc.es

(4) Professor do Instituto de Geociências e Ciências Exatas, Universidade Estadual de São Paulo - UNESP. CEP $13500-230$ Rio Claro (SP). E-mail: carvalho@rc.unesp.br

(5) Professor da Universidade Federal dos Vales do Jequitinhonha e Mucuri - UFVJM, Caixa Postal 38, CEP $39100-000$ Diamantina (MG). E-mail: christo@jknet.com.br 
serpentinizadas das regiões subtropicais e temperada. No processo de formação de solo, a evolução da trama segue a seguinte seqüência: alteração da rocha $\rightarrow$ trama frâgmica $\rightarrow$ trama porfírica com cavidades $\rightarrow$ trama porfírica aberta por coalescência de cavidades. O processo de argiluviação é evidente e se dá em dois estádios distintos: argiluviação primária, que ocorre nas fendas e cavidades que se formam por alteração de rocha, e argiluviação secundária, verificada na porosidade mais aberta e evoluída da coalescência das cavidades. Os solos apresentam mineralogia pouco comum para solos tropicais, com presença de minerais primários de fácil decomposição até mesmo na fração argila, com destaque para o talco, clorita trioctaedral e ocorrência limitada de tremolita, sendo esta última abundante na fração silte. Óxidos de Fe, caulinita e os interestratificados de clorita-esmectita e de clorita-vermiculita completam a assembléia mineralógica. A tendência de evolução é para $B$ textural ou para $B$ nítico com mineralogia 1:1 e alto conteúdo de óxidos de Fe. Nas fases iniciais de alteração, os alteromorfos já apresentam composição química similar aos agregados do solo, com forte perda de $\mathrm{Mg}$, Ca e Si e acúmulo relativo de Al e Fe. Nas três situações estudadas, ocorreu um rejuvenescimento superficial por erosão diferencial, que acumulou material grosseiro e removeu os finos, contribuindo para o incremento da relação textural.

Termos de indexação: pedogênese, rochas ultrabásicas; micromorfologia de solos; microanálises por EDRX, talco em solos.

\section{SUMMARY: GENESIS OF SOILS FORMED FROM ULTRAMAFIC SERPENTINIZED ROCKS IN SOUTHWESTERN MINAS GERAIS (BRAZIL)}

Soils formed from serpentinized rocks or serpentinites constitute a special group of soils on the earth surface. These rocks present ultramafic characteristics, with more than $70 \%$ mafic minerals (iron and magnesium oxides). The mineralogy of serpentinites is poor in silica and aluminum and very rich in $\mathrm{Mg}$. Only few studies have looked into the morphology, mineralogy, genesis and classification of soils developed on this type of parent material. In the humid-tropical climate of southwestern Minas Gerais state, three representative soil profiles were taken from the Morro do Ferro, in the Greenstone Belt area, on young geomorphic surfaces. They were characterized by macro and micromorphological descriptions, particle size distribution and chemical analysis, and $X$ ray mineralogical analysis of the clay and sand fractions. The geochemical alterations in the soil horizons were characterized by EDRX microanalyses of soil thin sections. The soils were classified as Haplic Phaeozern Eutric Regosol and chromic Cambisol. Although these soils are developed in a climate that favors quick weathering, from a morphological and mineralogical point of view they are similar to soils derived from serpentinized rocks in sub-tropical and temperate regions. The process of soil formation shows an evolution of the related distribution as follows: rock alteration $\rightarrow$ fragmic related distribution $\rightarrow$ vughy porphyric related distribution $\rightarrow$ open porphyric related distribution due to vugh coalescence. Argilluviation is evident and appears in two different phases: primary argilluviation that occurs between fissures and vughs formed by rock alteration and secondary argilluviation found in the more open and evolved coalesced vughs. The mineralogy of these soils is somewhat uncommon for tropical soils, with the presence of easily weatherable primary minerals in the clay fraction, especially talc, trioctahedral chlorite and, to a lesser extent, tremolite. The latter is abundant in the silt fraction. Iron oxides, kaolinite and chlorite-smectite and chlorite-vermiculite interlayers complete the mineralogical assembly. The evolution tends towards an argilic B horizon with 1:1 clay mineralogy and high iron oxide contents. In the initial weathering stages the chemical composition of the alteromorphs is similar to the soil aggregates, with a strong loss of $\mathrm{Mg}, \mathrm{Ca}$ and $\mathrm{Si}$ and relative $\mathrm{Al}$ and $\mathrm{Fe}$ accumulation. In all studied situations a superficial re-juvenescence due to differential erosion had occurred. This process led to the accumulation of coarse particles and removal of fine material, contributing to the increment of the textural gradient.

Index terms: pedogenesis, ultrabasic rocks, soil micromorphology, EDRX microanalysis; talc in soils. 


\section{INTRODUÇÃO}

Um grupo especial de solos da superfície terrestre é o derivado de rochas serpentinizadas ou serpentinitos. De caráter ultramáfico, ou seja, apresentando mais de $70 \%$ de minerais máficos (ferromagnesianos), os serpentinitos revelam uma mineralogia pobre em sílica e escassa em alumínio, sendo, no entanto, muito enriquecida em $\mathrm{Mg}$ e em alguns metais pesados como $\mathrm{Cr}, \mathrm{Ni}$ e Co. Além disso, as serpentinas, minerais principais dessa rocha, são formadas em condições de temperatura e pressão (hidrotermalismo ou metassomatismo) mais próximas às condições de superfície, o que lhes confere maior estabilidade em relação à maioria dos demais minerais primários intemperizáveis. O nome serpentina define o subgrupo de minerais filossilicatos 1:1 trioctaedrais preenchidos por cátions diversos, como $\mathrm{Mg}^{2+}, \mathrm{Fe}^{2+}, \mathrm{Fe}^{3+}, \mathrm{Mn}^{2+}, \mathrm{Zn}$, $\mathrm{Ni}$ e Al. A proporção destes cátions octaedrais define qual mineral do subgrupo será formado, sendo os mais freqüentes o crisotilo, a lizardita e a antigorita, todos com a fórmula química próxima de $\mathrm{Mg}_{3} \mathrm{Si}_{2} \mathrm{O}_{5}(\mathrm{OH})_{4}$ (White \& Dixon, 2002).

Essa constituição química e mineralógica de material de origem dá lugar, em condições climáticas variadas, a solos pouco espessos, por vezes pedregosos, com grau variável de desenvolvimento do horizonte do B e com uma constituição química e mineralógica especial, com uma importante presença de minerais herdados, tais como: a clorita, o talco e a serpentina (Alexander et al., 1985). Do ponto de vista de fertilidade, o predomínio do $\mathrm{Mg}$ em relação ao $\mathrm{Ca}$ provoca importantes desequilíbrios nutricionais que coincidem, também nesses solos, com os provocados pelos teores muito baixos de P, K e Mo. Freqüentes são também nesses solos ocorrências de alguns metais pesados, como o Ni, Cr e o Co (Proctor \& Woodell, 1978).

Esse quadro edáfico foi descrito em muitas regiões de clima temperado, tendo, como exemplos, os trabalhos de Alexander et al. (1985, 1988), Rabenhorst et al. (1982), nos EUA, e Calvo de Anta et al. (1987) e Bonifácio et al. (1997), na Espanha e na Itália, respectivamente. Também em regiões frias, Bulmer et al. (1992) e Adamson et al. (1993) descreveram solos com características similares aos da região temperada.

Já para a região tropical, muitos estudos apontam para a natureza laterítica dos profundos mantos de alteração que ocorrem sobre rochas ultramáficas com variável grau de serpentinização (Trescases, 1975; Segalen et al., 1980; Beinroth, 1982). Em consonância com esses estudos, têm sido reportadas no Brasil diversas ocorrências de solos muito intemperizados, profundos e com jazimentos niquelíferos desenvolvendo sobre rochas ultramáficas (Melfi et al., 1980; Oliveira \& Trescases, 1980). Aparentemente, tais ocorrências estão sempre associadas a remanescentes de antigas superfícies de aplainamento, como são, no Brasil, as superfícies Velhas e Sul Americana (Oliveira, 1990).
Contrastando com as ocorrências das lateritas niquelíferas, alguns trabalhos mostram que, no Brasil, ocorrem também solos derivados de rochas serpentinizadas semelhantes aos das regiões temperadas. É o caso da região subtropical do Rio Grande do Sul, onde Meneggoto (1983) e depois Pinto \& Kämpf (1996) descreveram solos poucos profundos, com pedregosidade e mineralogia tal que esses autores passaram a considerar tais solos como "os menos intemperizados do Rio Grande do Sul". Por outro lado, na região semi-árida do Brasil, foram descritos solos derivados de serpentinitos e ultramáficas associadas com mineralogia esmectítica e com forte contribuição de minerais herdados (Oliveira \& Trescases, 1980; Oliveira, 1990). Em ambos os casos, tanto no RS como no sertão do Piauí, os estudos foram feitos sobre superfícies geomórficas recentes, rejuvenescidas pela erosão.

Em trabalhos de campo, realizados para estudos de natureza geológica no greenstone belt Morro do Ferro (Carvalho et al., 1993), no sudoeste de Minas Gerais, região de clima tropical úmido, muitas das ocorrências de serpentinitos foram facilmente mapeadas em razão do controle estrutural do relevo exercido por estas rochas, com afloramentos rochosos e presença de solos poucos profundos, situação semelhante à descrita para o ambiente temperado $\mathrm{e}$ subtropical (Alexander et al., 1985; Pinto \& Kämpf, 1996). Embora existam muitas rochas ultramáficas na região tropical e no Brasil em particular, há poucos registros a respeito da morfologia, gênese e classificação dos solos desenvolvidos sobre essas rochas.

O objetivo deste trabalho é descrever a morfologia, mineralogia e classificação desses solos, assim como identificar processos pedogenéticos dominantes.

\section{MATERIAL E MÉTODOS}

\section{Descrição do meio físico}

O planalto do Sul de Minas ou Planalto do Rio Grande distribui-se a noroeste da Serra da Mantiqueira, alonga-se até às cabeceiras do Rio São Francisco e para oeste até ser recoberto pelos sedimentos da Bacia do Paraná. É caracterizado por uma ampla superfície ondulada, talhada essencialmente em rochas do complexo gnáissico-migmatítico, com altitudes em torno de $900 \mathrm{~m}$, sendo interrompida por uma série de cristas adaptadas às orientações gerais dos gnaisses, atingindo cotas superiores a $1.000 \mathrm{~m}$.

Ao norte do Planalto Sul de Minas, desenvolveu-se a Serra de Canastra, formada por uma série de espigões quartzíticos seccionados por uma superfície aplainada residual de cerca de $1.300 \mathrm{~m}$. Trata-se de um importante divisor de águas que separa as bacias dos rios São Francisco e Grande. 
Particularmente, nas áreas investigadas em Fortaleza de Minas e em Alpinópolis, a morfologia do relevo acha-se condicionada amplamente às feições geológicas: na região do embasamento, o relevo é bastante dissecado com cristas alongadas segundo a direção dos principais lineamentos estruturais, evidenciando uma evolução das formas sob controle tectônico. O cinturão ultramáfico distribui-se em um corredor de relevo colinoso, onde se destacam cristas alinhadas, sustentadas por meta-chert, com altitudes em torno de $1.000 \mathrm{~m}$. A morfologia do embasamento contrasta-se com cristas elevadas de quartzito do Grupo Canastra, cujas expressões morfológicas são representadas pelas Serras do Chapadão, Ventania e São João, que alcançam a altitude de 1.200 m. A drenagem dendrítica retangular, ou padrão retilíneo paralelo, reflete o sistema de fraturas secundárias. A área conta com intensa densidade de drenagem, integrada na bacia do rio São João, afluente do Rio Grande.

Após um trabalho intensivo de campo verificando as ocorrências de solos pouco profundos sobre serpentinitos na região estudada, muito similares em morfologia aos descritos na bibliografia internacional sobre solos derivados dessas rochas, foram escolhidos três pedons, que representam as variações de relevo, litologia e vegetação existente na região. As áreas escolhidas para o estudo estão em diferentes locais do greenstone belt "Morro do Ferro", nas proximidades dos municípios de Fortaleza de Minas (Perfil 1, P1) e Alpinópolis (Perfis 2 e 3, P2 e P3) (Figura 1). A associação rochosa de natureza vulcano-sedimentar que compõe o greenstone belt retromencionado encontrase embutida tectonicamente por falhas ou por outras estruturas sinformais em um embasamento graníticomigmatítico-gnáissico arqueano, regionalmente denominado Complexo Campos Gerais (Carvalho et al., 1993). As unidades litológicas estudadas, além de serpentinitos, localmente contêm também outros litotipos, tais como: talco-xisto e cherts de natureza diversa, podendo ocorrer, ainda, intercalações com granito/gnaisses e anfibolitos (Figura 1).

Segundo Carvalho et al. (1993), os serpentinitos da área derivam-se de peridotitos komatiiticos. As

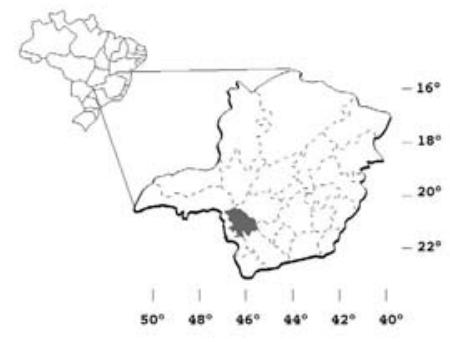

LEGENDA

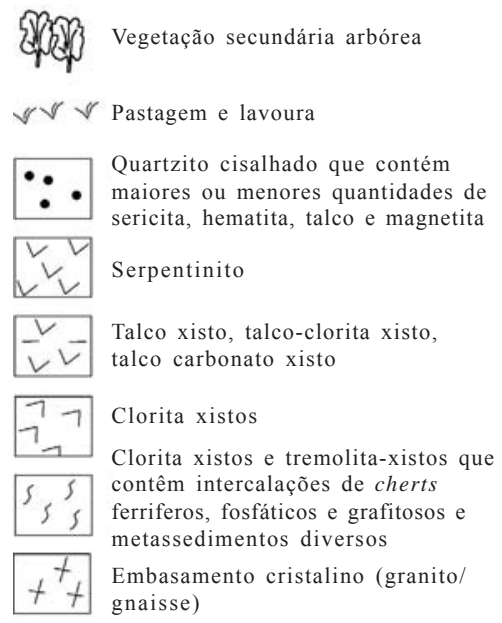

\section{Fortaleza de Minas}

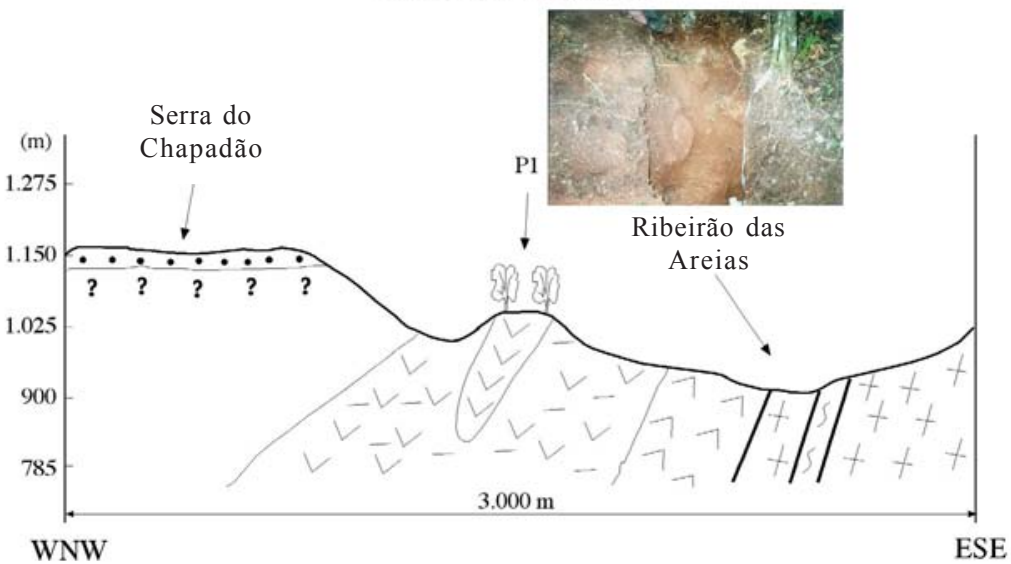

Alpinópolis

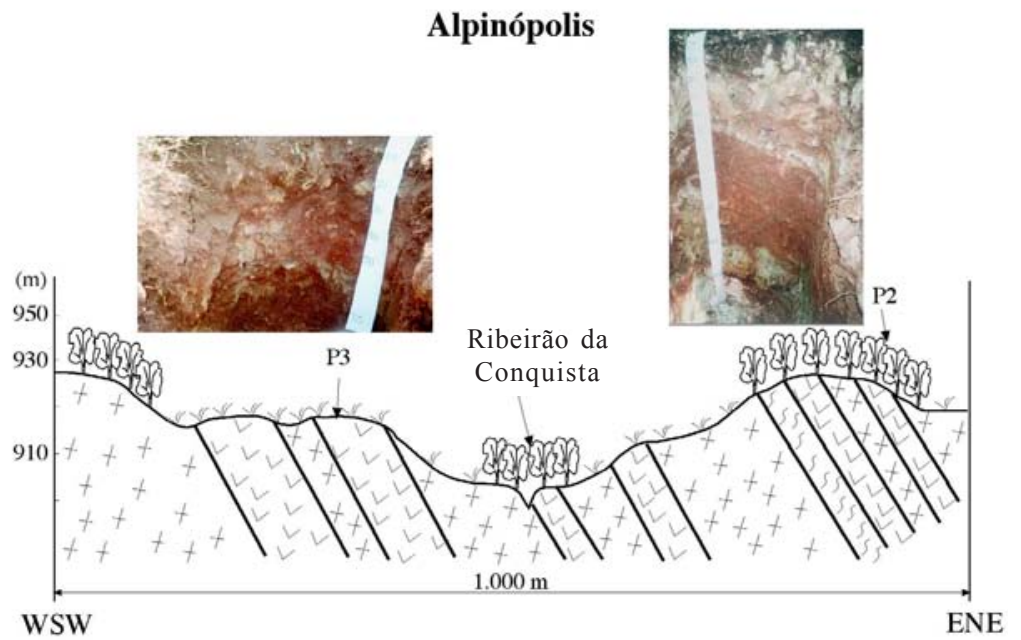

Figura 1. Localização da área de estudo e representação esquemática do relevo, litologia e situação dos perfis estudados. 
serpentinas derivam diretamente de olivinas e indiretamente de talco, tremolita, actinolita e clorita, quando esses minerais representam fases intermediárias de alterações das olivinas. De forma geral, os serpentinitos em ambas as áreas apresentam a composição mineralógica de: serpentina (30-90 \%), actinolita/tremolita $(0-40 \%)$, clorita $(0-18 \%)$, opacos $(5-15 \%)$, carbonatos $(0-12 \%)$, olivina $(0-5 \%)$, talco (0-1\%) e clinopiroxênio (0-1\%).

A região apresenta clima tropical de altitude $\mathrm{Cwb}$ (mesotérmico, com verões brandos e estacão seca de outono-inverno), segundo classificação de Köeppen. As médias anuais de precipitação e temperatura são de $1.500 \mathrm{~mm}$ e $20^{\circ} \mathrm{C}$, respectivamente. As chuvas são mais freqüentes de outubro a abril e o período mais seco é de junho a agosto, com precipitações médias mensais entre 150 e $250 \mathrm{~mm}$ e entre 25 e $30 \mathrm{~mm}$. A temperatura média dos meses mais frios (junho-julho) é de $15^{\circ} \mathrm{C}$ e a dos meses mais quentes (dezembro a março) de 22 a $23^{\circ} \mathrm{C}$. Embora secundária, a vegetação nativa está presente e se trata de floresta estacional semidecidual, com elementos de savana florestada.

\section{Situação e localização}

Foram escolhidas três áreas de estudo no sudeste de Minas Gerais. A primeira delas situa-se no município de Fortaleza de Minas, em local muito próximo às escarpas quartzíticas da Serra da Fortaleza. O relevo dominante é ondulado e a litologia muito complexa, o que é próprio do greenstone belt que ocorre na região. O perfil 1 situa-se em uma área com vegetação natural do tipo floresta estacional semidecidual, situação do topo de uma colina local, com pouca possibilidade de colúvios e desenvolvido sobre rochas tipicamente serpentinizadas que constituem um corpo circundado por talco xistos. Os solos são rasos com pedregosidade e rochosidade na superfície.

O perfil 2 situa-se no município de Alpinópolis (MG), distante $30 \mathrm{Km}$ do anterior. Situa-se no topo de uma colina intermediária do vale do Ribeirão da Conquista, com relevo mais suave que o local do perfil 1, e apresenta vegetação secundária. Neste local, os corpos dos serpentinitos se entrecruzam com rochas gnáissicas, xistos diversos e anfibolitos. O solo também é pouco profundo e apresenta pedregosidade e rochosidade como o perfil 1.

O perfil 3 está situado próximo do perfil 2, do qual dista $600 \mathrm{~m}$ (Figura 1). Trata-se de área de pastagem com ocorrência localizada de pequenos arbustos e, assim como em P1 e P2, também apresenta pedregosidade e blocos de serpentinito aflorantes.

Após estudos morfológicos das três áreas, desenhouse, no campo, o perfil topográfico e pedológico representativo. Para tanto, usaram-se trado, clinômetro, trena e observação detalhada de transições regolito/rocha em trincheiras. Para esta finalidade, escolheu-se a área 1 em Fortaleza de Minas.

\section{Morfologia e análise de rotina}

Os perfis foram descritos de acordo com Lemos \& Santos (1996), com algumas adaptações para descrição dos agregados de solos. Após identificação e descrição dos horizontes, foram coletadas as amostras indeformadas para micromorfologia e, depois, as amostras deformadas para as análises de laboratório. Fragmentos de rocha aparentemente sã e de outras mais alteradas com córtex bem preservado de alteração foram cuidadosamente coletados.

As amostras de terra foram secas ao ar, destorroadas e passadas por peneiras de malha de 2 $\mathrm{mm}$ (terra fina seca ao ar - TFSA), as quais foram submetidas às seguintes análises:

- Granulometria: após agitação horizontal por 16h, determinou-se o teor de argila e silte pelo método de densímetro, utilizando-se, como dispersante, solução que continha hidróxido de sódio e hexametafosfato de sódio (Camargo et al., 1986). A areia foi pesada e depois peneirada, obtendo-se cinco frações.

- Análise química: determinaram-se $\mathrm{pH}$ em $\mathrm{H}_{2} \mathrm{O}$, matéria orgânica, cátions trocáveis $(\mathrm{Ca}, \mathrm{Mg}, \mathrm{K}$, Al), de acordo com Raij et al. (1987), e acidez potencial $(\mathrm{H}+\mathrm{Al})$, pelo método de acetato de cálcio.

\section{Mineralogia do solo}

Em amostras selecionadas dos horizontes dos solos, foi determinada a composição mineralógica das frações silte e argila, que foram analisadas sob a forma de pó e de agregado orientado, respectivamente. Todo o preparo e os tratamentos das amostras seguiram o método de Jackson (1969). Após eliminação da matéria orgânica e dos óxidos de ferro, a fração argila $(<2 \mu \mathrm{m})$ foi separada por sifonagem. Subamostras foram saturadas por $\mathrm{K}^{+}$e irradiadas na temperatura ambiente, após aquecimento a 350 e $550{ }^{\circ} \mathrm{C}$. As saturadas por $\mathrm{K}^{+}$ou por $\mathrm{Mg}^{2+}$ foram irradiadas com raios $\mathrm{X}$ através de difratômetro Rigaku, com tubo de $\mathrm{Cu}$ e filtro de $\mathrm{Ni}$, no intervalo $2 \theta$ de 3 a $32^{\circ}$. As subamostras saturadas por $\mathrm{K}^{+}$foram irradiadas na temperatura ambiente e após aquecimento a 350 e $550^{\circ} \mathrm{C}$. As saturadas por $\mathrm{Mg}^{2+}$ foram irradiadas na temperatura ambiente em duas etapas, depois da solvatação com etilenoglicol, respectivamente. O silte foi analisado sob a forma de pó e as argilas na forma de agregado orientado.

\section{Micromorfologia, petrografia e microanálises químicas}

Amostras indeformadas do horizonte B dos solos e de amostras de rochas alteradas encontradas nos perfis foram impregnadas com resina de poliéster (Castro et al., 2003), a partir das quais se confeccionaram seções delgadas para análise micromorfológica. As descrições para os solos foram feitas, utilizando os critérios estabelecidos por Brewer (1976), com adaptações para 
a descrição da trama do solo, segundo Stoops \& Jongerius (1975). Para as fotomicrografias, empregouse um fotomicroscópio Zeiss. As amostras de rocha (aparentemente sã) encontradas foram cortadas e prepararam-se lâminas delgadas para observação da mineralogia em microscópio petrográfico. Com a finalidade de verificar o grau de serpentinização e se a composição mineralógica essencial das rochas que dão origem aos solos estudados é parecida, são apresentadas descrições petrográficas sucintas de cada rocha coletada.

Após o estudo micromorfológico do horizonte B dos solos, foram selecionados campos representativos das principais feições pedológicas e das distintas fases de alteração. Nesses campos, verificou-se a distribuição espacial dos elementos químicos constituintes por meio de um sistema com detector de raios X por dispersão de energia (EDRX) acoplado a um microscópio eletrônico de varredura (MEV) LEO. Três procedimentos foram adotados: análise química total, obtendo-se o espectro geral (qualitativo) do campo analisado; análise química pontual (spot analysis), obtendo-se o espectro geral de um pequeno campo dentro da imagem e, por último, mapeamento por elemento do campo analisado (mapping analysis), utilizando a energia dispersiva característica dos elementos escolhidos. Os resultados das análises espectrais são representados em forma de gráficos e os dos mapeamentos em forma de imagens. Para melhor visualização, as imagens foram tratadas, previamente por meio do programa Corel photopaint para inversão das cores.

\section{RESULTADOS E DISCUSSÃO}

\section{Descrições petrográficas}

As descrições petrográficas das lâminas delgadas, confeccionadas a partir das amostras coletadas nos diferentes perfis, mostram que o material de origem, isto é, as rochas ultramáficas da região, apresentam grau variável e heterogêneo de serpentinização, com variação na proporção de minerais essenciais e acessórios (Quadro 1, Figura 2), sendo a tremolita, o talco, a clorita e a serpentina os minerais comuns aos três litotipos estudados.

A serpentina do solo provavelmente é herdada da rocha, visto que, no exame petrográfico, mostrou ser predominantemente antigorita (Quadro 1). No caso geral, é originada de serpentinas magnesianas de grupo $\mathrm{Mg}_{3} \mathrm{Si}_{2} \mathrm{O}_{5}(\mathrm{OH})_{4}$.

\section{Morfologia dos solos}

Os solos mostraram-se similares, morfologicamente, aos descritos para os ambientes temperados, com pouca profundidade, fraco desenvolvimento do horizonte B, pedregosidade e afloramentos rochosos (Quadro 2). A figura 3 ilustra a configuração lateral desses solos, representada a partir de uma trincheira de $5 \mathrm{~m}$ aberta em P1. O contato com a rocha $(\mathrm{R})$ é irregular e a sua topografia e superfície configuram um microrrelevo pseudocárstico, característico -de rochas que sofrem dissoluções congruentes.

Os três locais escolhidos para estudo apresentam, em seu entorno, a mesma variação espacial demonstrada na figura 3 para o perfil 1 . As variações laterais encontradas nos diferentes locais estão mais associadas às transições entre os serpentinitos e às respectivas rochas encaixantes (talco-xisto em $\mathrm{P} 1$, granito e anfibolitos em P2 e P3). A descrição morfológica sucinta dos três perfis está representada no quadro 2 .

Nos três perfis, o horizonte A é escuro e apresenta significativa acumulação de matéria orgânica. Sua espessura é irregular, com grande quantidade de pequenos fragmentos de rocha com avançado grau de alteração. Em P1, esse horizonte é mais espesso e chega a constituir um A chernozêmico com $30 \mathrm{~cm}$ de espessura no local onde foi descrito (Figuras 1 e 3 )

De maneira geral, o horizonte $\mathrm{B}$ desses solos tem uma pedalidade moderada e, assim como nos horizontes superiores, apresenta fragmentos de rocha de alguns milímetros a vários centímetros misturados à massa do solo, porém visivelmente menos alterados

\section{Quadro 1. Descrição petrográfica das seções delgadas das rochas}

Amostra Descrição petrográfica sucinta

Perfil 1 Serpentinito com restos de tremolita grosseira e clorita, pontuações de talco e minerais opacos. A serpentina é representada basicamente por antigorita, aparecendo localmente crisotilo (Figura 2a e $2 b)$.

Perfil 2 Serpentinito com restos de tremolita e clorita, tendo como acessórios cristais de minerais opacos (Figura 2c).

Perfil 3 Rocha composta basicamente por tremolita com granulação fina pouco orientada, aparecendo manchas de serpentinito com restos de olivina (olivina serpentinizada), cristais de ortopiroxênios relativamente grandes e clinopiroxênio fraturados e corroídos, parcialmente alterados para talco, palhetas de clorita, às vezes, com geminação e kink bands, espinélio verde e minerais opacos. Tratase tremolita xisto ou fels ou meta olivina websterito (Figura 2d a 2f). 

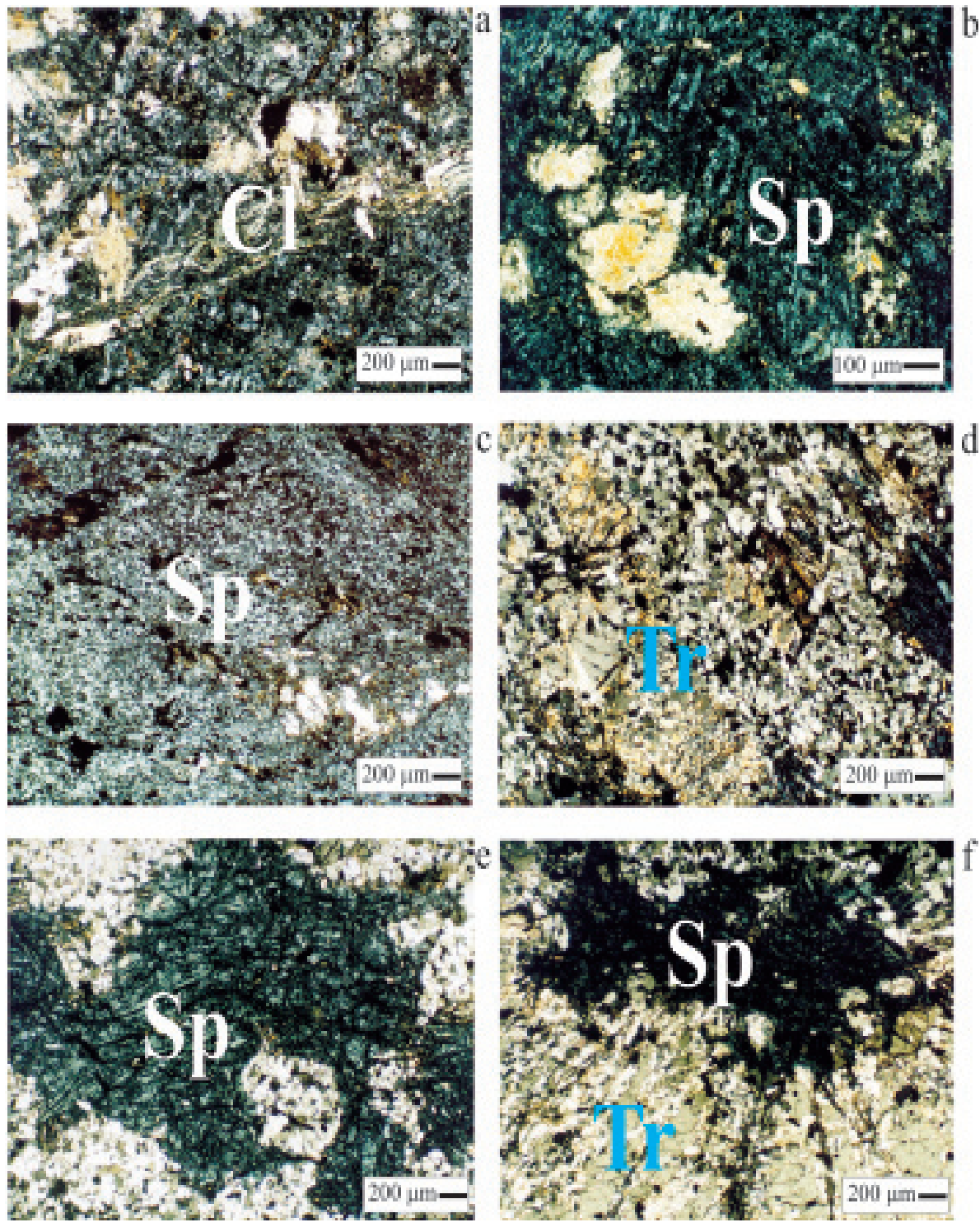

Figura 2. (a): Fotomicrografias sob luz poralizada das rochas coletadas em P1, P2 e P3 e (b): serpentinito com restos de tremolita grosseira e clorita (Cl) em P1; c: serpentinito com restos de tremolita e clorita em P2; de e f: tremolita xisto com manchas de serpentinito no P3. Sp: serpentina; Tr: tremolita; Cl: clorita.

que nos dois horizontes mais superficiais. A maior, ou menor, preservação de rocha em cada perfil poderia estar associada a seu padrão de fraturamento e, de forma especial, ao grau de serpentinização da rocha ultrabásica. Os fluxos serpentinizantes ocorrem por alterações hidrotermais e, como se vê na figura 2, resultam em uma serpentinização irregular de rocha, corroborando observações de Coleman \& Jove (1991) e de Malpas (1991).

Agregados pequenos e granulares são freqüentes na superfície dos fragmentos de rocha alterada em todos os perfis, o que, provavelmente, está associado à intensa atividade de fauna do solo.

Nos três perfis, foram constatadas feições de revestimentos, porém estas ocorrem de forma irregular e são mais facilmente identificáveis na superfície de alguns agregados e de fragmentos de rocha alterada, nos horizontes B e C. Estes revestimentos estão associados a uma cor vermelha mais intensa na observação com lupa de $10 \mathrm{X}$ no campo, no caso de superfície de rochas alteradas e menos vermelhas, mais com um brilho tênue e mais facilmente identificável na superfície de alguns agregados. A cerosidade, quando identificada, não passou de fraca a moderada e em volumes restritos, principalmente nos perfis 1 e 3 .

A textura nos diferentes horizontes varia de média a argilosa, com horizontes que apresentam certa sedosidade, o que indica, já no campo, a presença de teores de silte muito elevados. 


\section{Quadro 2. Descrições morfológica sucinta dos perfis estudados}

\begin{tabular}{|c|c|c|c|}
\hline Profundidade & Horizonte & Cor Munsell & Descrição \\
\hline $\mathrm{cm}$ & & & P-1 Mata, Fortaleza de Minas (MG) \\
\hline-10 a 0 & $\mathrm{O}$ & 5,0 YR $2,5 / 1$ & $\begin{array}{l}\text { Serapilheira composta de abundantes raízes menores que } 2,0 \mathrm{~mm} \text {; } \\
\text { bastante material altamente humificado presente. }\end{array}$ \\
\hline $0-10$ & $\mathrm{~A} 1$ & $2,5 \mathrm{YR} 2,5 / 0$ & $\begin{array}{l}\text { Estrutura granular, pequena ccom abundância de raízes de diferentes } \\
\text { tamanhos e presença de fragmentos de rocha (serpentinitos) bastante } \\
\text { alterados (2 a } 10 \mathrm{~cm} \text { de diâmentro), os quais podem ser cortados com a } \\
\text { faca. Raízes e fragmentos de rochas são tão abundantes que } \\
\text { impossibilitam coleta de amostra indeformada. Alguns matações de } \\
\text { serpentinito afloram na superfície. Transição irregular e clara. }\end{array}$ \\
\hline $10-30$ & $\mathrm{~A} 2$ & 2,5 YR $2,5 / 3$ & $\begin{array}{l}\text { Estrutura subangular pequena + granular moderada a fraca. Raízes } \\
\text { grandes (maiores que } 1 \mathrm{~cm} \text { ) abundantes. Blocos de rocha, com distintos } \\
\text { graus de alteração, dispersos em todo o perfil, porém com disposição } \\
\text { paralela à superfície. }\end{array}$ \\
\hline $30-50$ & $\mathrm{AB}$ & $2,5 \mathrm{YR} 3 / 4$ & $\begin{array}{l}\text { Grande quantidade de fragmentos de rocha alterada de tamanho } \\
\text { centimétrico }(2 \text { a } 20 \mathrm{~cm}) \text { que podem ser cortados pela faca. Agregação } \\
\text { mais desenvolvida: subangular, pequena, moderada com alguma } \\
\text { cerosidade. }\end{array}$ \\
\hline $50-90$ & $\mathrm{Bi}$ & $2,5 \mathrm{YR} 3 / 6$ & $\begin{array}{l}\text { Os agregados são predominantemente subangulares, pequenos a } \\
\text { médios, com grau de agregação moderado a fraco. Este horizonte não } \\
\text { aparece em todas as faces da trincheira, com transição para a rocha em } \\
\text { forma de línguas. }\end{array}$ \\
\hline $90-110$ & $\mathrm{BC}$ & $2,5 \mathrm{YR} 3 / 6$ & $\begin{array}{l}\text { Friável, com aspecto maciço, com manchas amarelas que gradam para } \\
\text { córtex de alteração (horizonte C) de forma gradual a clara e este de } \\
\text { forma abrupta para núcleo da rocha cinza dura, a qual não pode ser } \\
\text { cortada com faca. Transição irregular para horizonte C. }\end{array}$ \\
\hline \multirow[t]{2}{*}{$110-130$} & $\mathrm{C}$ & $5 Y R$ a $7,5 Y R$ & $\begin{array}{l}\text { Aspecto maciço, friável, sem agregação evidente. Transição abrupta e } \\
\text { irregular para R. }\end{array}$ \\
\hline & & & P-2 Mata, Alpinópolis (MG) \\
\hline-5 a 0 & $\mathrm{O}$ & 10YR 3/1 & Serapilheira. \\
\hline $0-10$ & $\mathrm{Al}$ & 10YR $3 / 2$ & $\begin{array}{l}\text { Grande quantidade de rocha alterada misturada com terra agregada } \\
\text { granular, pequena de grau moderado, raízes abundantes. }\end{array}$ \\
\hline $10-50$ & $\mathrm{CB}$ & $7,5 \mathrm{YR} 4 / 4$ & $\begin{array}{l}\text { Horizonte constituído por } 80 \% \text { de fragmentos de rocha alterada; a } \\
\text { terra foi coletada nos espaços entre as rochas. Transição clara e } \\
\text { inclinada } 30^{\circ} \text { de mergulho em relação à superfície. }\end{array}$ \\
\hline $50-80$ & $\mathrm{Bi}$ & $5 \mathrm{YR} 3 / 4$ & $\begin{array}{l}\text { Agregados subangulares e pris máticos, pequenos e médios com grau } \\
\text { moderado a fraco. Friável, com sedosidade ao tato. Transição clara e } \\
\text { paralela à superior. }\end{array}$ \\
\hline $80-130$ & $\mathrm{BC}$ & $5 \mathrm{YR} 3 / 4$ & $\begin{array}{l}\text { Horizonte com grande quantidade de fragmentos de rocha alterada, } \\
\text { conservando a estrutura da rocha, a qual tem a mesma orientação das } \\
\text { transições supradescritas. }\end{array}$ \\
\hline $130-150$ & $\mathrm{CR}$ & & $\begin{array}{l}\text { Placa de rochas em estado variável de alteração com espessura } \\
\text { centimétrica e inclinadas em relação ao prumo do perfil tal como no } \\
\text { horizonte CB. Transição inclinada e abrupta. }\end{array}$ \\
\hline \multirow[t]{2}{*}{$150-175$} & $2 \mathrm{C}^{(1)}$ & $2,5 \mathrm{Y} 8 / 2$ & $\begin{array}{l}\text { Aspecto maciço, muito friável, arenoso com argila e silte: Areia (?) } \\
\text { branca de alteração de rocha granítica. }\end{array}$ \\
\hline & & & P-3 Pastagem, Alpinópolis (MG) \\
\hline $0-10$ & Ap & 7,5 YR $3 / 4$ & $\begin{array}{l}\text { Estrutura subangular pequena e granular muito pequena, moderado. } \\
\text { Raízes finas abundantes, mescladas pivotantes e faciculadas. Transição } \\
\text { clara. }\end{array}$ \\
\hline $10-40$ & Bil & $5 \mathrm{YR} 3 / 3$ & $\begin{array}{l}\text { Fragmentos de rocha alterada, pode ser cortado com a faca, abundantes } \\
\text { e com tamanho centimétrico. Agregados de solo (blocos pequenos de } \\
\text { grau fraco e moderado) entre os comuns fragmentos de rocha alterada. } \\
\text { Transição clara e irregular. }\end{array}$ \\
\hline $40-70$ & $\mathrm{Bi} 2$ & 5 YR $3 / 4$ & $\begin{array}{l}\text { Horizontes com zonas de alteração que apresentam cores muito } \\
\text { variadas: manchas pretas e outras vermelho - vivo, com certo brilho } \\
\text { (cerosidade ?) contrastando com matriz cinza esverdeado. Transição } \\
\text { abrupta para horizonte CR. }\end{array}$ \\
\hline
\end{tabular}

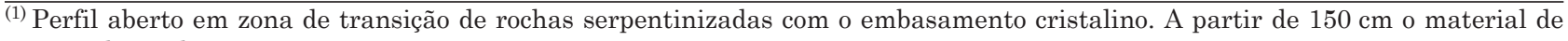
origem deixa de ser o serpentinito. 


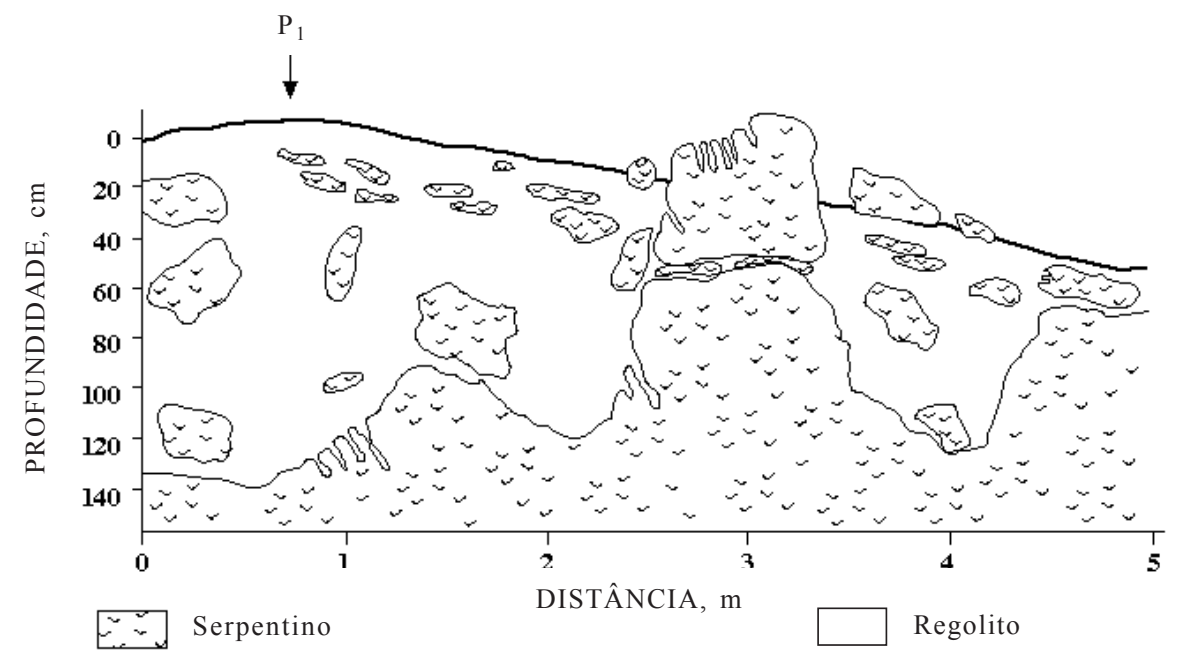

Figura 3. Perfil lateral avaliado em trincheira do regolito no topo da colina estudada em Fortaleza de Minas (MG). Notem-se a variação de espessura e o fendilhamento tanto na superfície do bloco de rocha aflorante como em algumas posições na transição rocha/solo (microrrelevo pseudocárstico característico de rochas que sofrem dissoluções congruentes).

\section{Micromorfologia do horizonte B}

Para elucidar os processos pedogenéticos envolvidos, optou-se por descrever, microscopicamente, as principais feições pedológicas e os aspectos evolutivos da trama do solo desde a transformação dos minerais primários em secundários, com surgimento do plasma por alteração.

Os fragmentos de rochas com diferentes granulometrias, percebidos no campo, aparecem em todas as lâminas com grau variável de alteração. Também se verificou a irregularidade do processo de serpentinização desses fragmentos de rocha, tal como pôde ser verificado nas descrições petrográficas.

O grau fraco a moderado de agregação descrito para os horizontes $\mathrm{B}$, assim como o tamanho variável dos agregados, é refletido nas descrições de tramas que variam entre gefúrica, frágmica e porfírica. Os agregados têm conteúdo de silte mais elevado que o normal para solos tropicais e isso diminui a ação cimentante das partículas de argila, diminuindo a estabilidade dos agregados, sendo uma das causas da baixa pedalidade destes solos.

À evolução inicial do plasma a partir da rocha serpentinizada, segue-se a formação de volumes pedogeneizados (Figuras 4 e 5), com uma posterior fragmentação dos agregados, como pode ser visto na trama frágmica do Bi do P1 (Figura 4a) e P3 (Figura 4b). Esta trama inicial evolui para uma trama densa que domina os agregados do Bi dos três perfis, denominada trama porfírica (Figura 4c). Nas partes mais desenvolvidas do horizonte $\mathrm{B}$, a trama dominante é porfírica, porém, como são materiais que sofrem um processo de dissolução importante, surgem cavidades e intercomunicações entre estas, passando, então, a uma trama porfírica aberta por ação dessa coalescência de cavidades (Figura 4c).
Os agregados muitos pequenos e de consistência friável do horizonte B (microagregados), descritos com freqüência no campo no contato entre fragmentos de rocha alterados e solo, são, na sua maioria, resultado de dissolução congruente ou de microagregação provocada pela fauna do solo, principalmente pelas térmitas (Eschenbrenner, 1986; Miklós, 1992; VidalTorrado et al., 1999), que tipicamente formam agregados muito pequenos, de diâmetro em torno de $0,2 \mathrm{a} 1,0 \mathrm{~mm}$, ovais e, ou, muito arredondados (Figuras $4 \mathrm{~d}$ e $4 \mathrm{e}$ ).

A ferruginização intensa e localizada pode proteger o núcleo de fragmentos remanescentes de rocha (litorrelíquias) da ação do intemperismo preservandoos em seu interior, formando um revestimento que leva à oclusão e proteção da alteração dos minerais primários (Figuras $4 \mathrm{~g}$ e $4 \mathrm{~h}$ ).

Dois tipos de cutãs de iluviação (ferriargilãs) foram constatados: nas fendas e cavidades que se formam por alteração da rocha (Figura 5a a 5d), alteroiluviação ou argiluviação primária, e na porosidade evoluída a partir da coalescência de cavidades da trama porfírica do horizonte B ou argiluviação secundária (Figura 4d, 5e, 5f). Aparentemente, da primeira pouco se mantém nas partes mais evoluídas do horizonte $\mathrm{B}$, embora algumas pápulas encontradas inseridas na matriz porfírica testemunhem que os processos de argiluviação se dão ao menos em dois momentos distintos durante a pedogênese (Figura 4c). Outro aspecto observado é que, uma vez aberta a porosidade por coalescência de cavidades, a argiluviação é mais intensa, revestindo extensões maiores das paredes dos poros (Figura 4d e 5e).

Outro aspecto muito evidente são as feições de dissolução, gerando uma porosidade característica desse processo, como são as cavidades e, especialmente, as fissuras contínuas e de paredes tortuosas que 

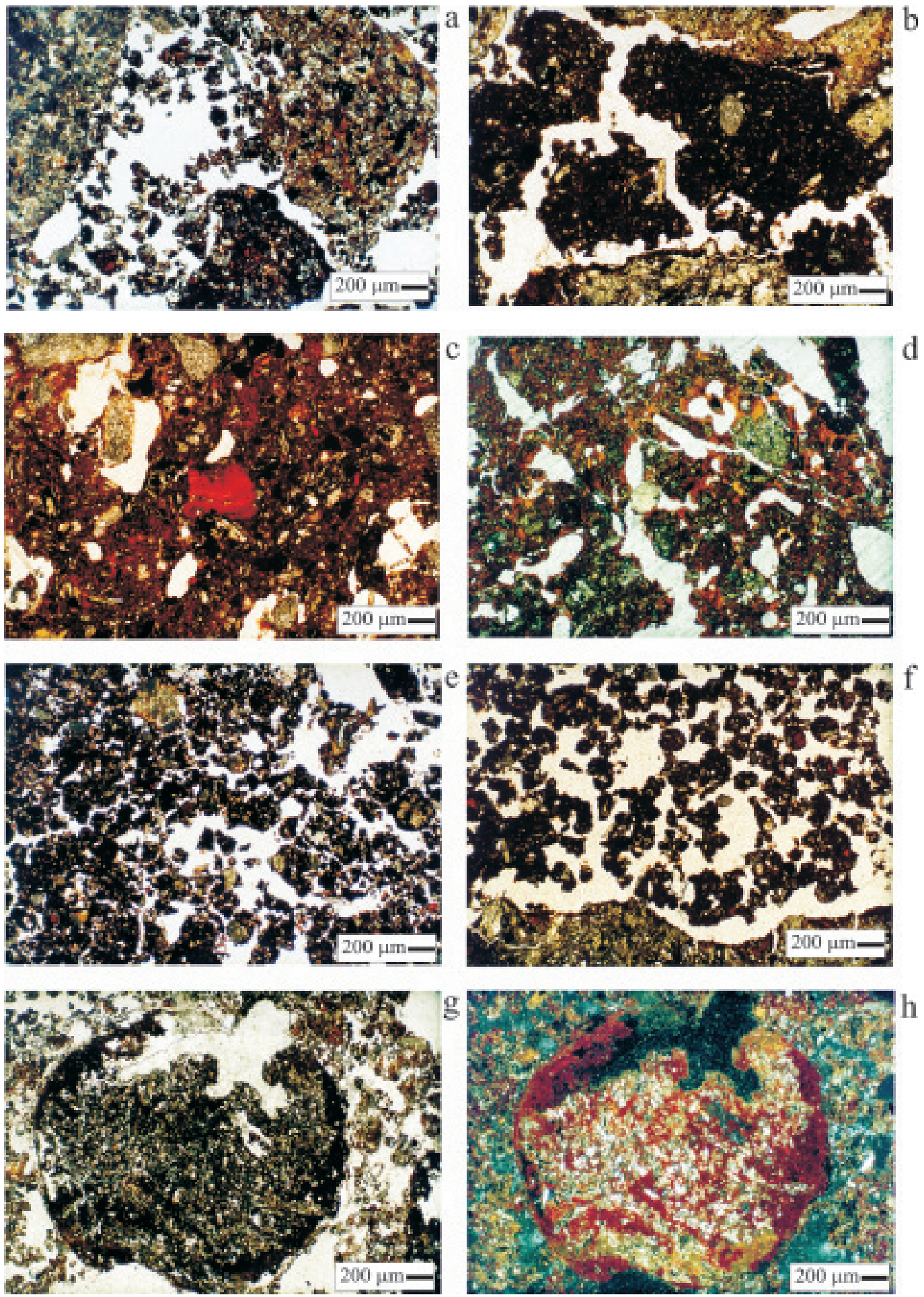

Figura 4. Fotomicrografias selecionadas de seções delgadas dos horizontes Bi dos três perfis estudados.

Foto $\mathrm{h}$ sob luz polarizada cruzada; demais fotos sob luz polarizada plana. Fotos a e b: trama frágmica inicial formada a partir da evolução da alteração da rocha; Foto c: trama pofírica com cavidades dominantes na maior parte dos agregados estudados nos três perfis. Note-se ao centro pápula de argiluviação incorporada à matriz; Foto d: trama porfírica aberta por coalescência de cavidades que ocorre nas partes mais evoluídas dos agregados; Foto e: microagregação originada por mecanismos de dissolução; Foto f: microagregação do plasma de origem biológica; Fotos g e h: Agregado ferruginizado com grande quantidade de material de rocha (litorrelíquias) com menor grau de alteração do que o entorno em seu interior (oclusão dos minerais primários) e feições de iluviação primária e alteração incipiente. 
existem não só nos campos onde aparece a estrutura da rocha (Figura 5c e 5d), mas também em alguns agregados de volumes mais desenvolvidos (Figura 5e).

O exame micromorfológico de parte do horizonte $\mathrm{B}$ do Perfil 2 permitiu verificar que esse solo recebe alguma contribuição do granito encaixante, uma vez que alguns domínios apresentam um conteúdo de quartzo anormal para estes solos e mesmo a presença de alguns feldspatos potássicos pôde ser verificada. Tal contribuição poderia se dar por remonte biológico do material, uma vez que as rochas encontradas no perfil, tanto na parte superior como na base, foram identificadas como serpentinitos.

Análises químicas das seções delgadas por mapeamento utilizando EDRX

A evolução geoquímica do perfil de alteração é discutida com detalhe por Vidal-Torrado (1999). No entanto, cabe salientar aqui as tendências observadas com as diferentes fases de alteração, considerando a mobilidade de cada elemento e a constituição química da rocha original.
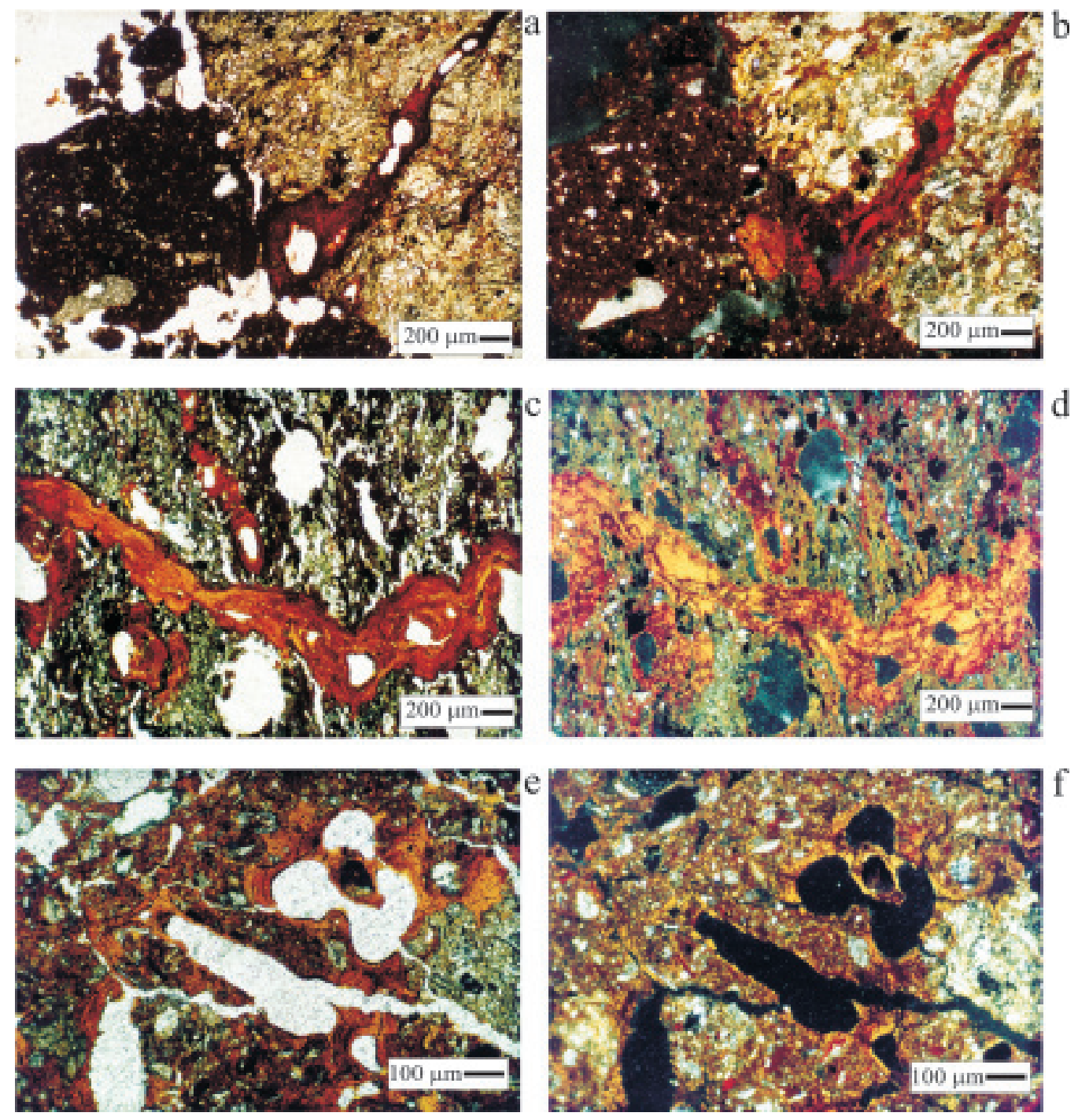

Figura 5. Fotomicrografias selecionadas de seções delgadas dos horizontes Bi dos 3 perfis estudados. Fotos a, c, e sob luz polarizada plana. Demais fotos sob luz polarizada cruzada. Fotos a e b: contato da rocha fissurada com a trama frágmica do Bi. Note-se que o preenchimento da fissura por cutãs de alteração e de iluviação (argiluviação primária); Fotos c e d: volume de horizonte Bi que sofreu forte dissolução da rocha e que tem ainda baixa pedalidade. Note-se o preenchimento com plasma vermelho advindo da alteração nos canais assim como a extinção estriada forte e contínua (foto d), típica de cutãs de argiliviação (argiluviação primária). Fotos e e f: cavidades e paredes da canais do horizonte Bi com revestimentos típicos de argiluviação secundária. Tais feições acorrem de forma localizada e somente quando a porosidade está mais aberta, ou seja, mais evoluída. 
A fotomicrografia da figura 6a ilustra três fases de alteração observadas no horizonte Bi do perfil 1: (a) rocha pouco intemperizada; (b) alteromorfo inicial e (c) alteromorfo final ou agregado de solo. A imagem de elétrons retroespalhados, representada na figura $6 \mathrm{~b}$, foi obtida em um microscópio eletrônico de varredura, tendo a fotomicrografia como referência. Os mapeamentos obtidos por dispersão de raios X (EDRX) para $\mathrm{Fe}, \mathrm{Al}, \mathrm{Mg}$, Si e Ca estão representados nas figura $6 \mathrm{c}, 6 \mathrm{~d}, 6 \mathrm{e}, 6 \mathrm{f}$ e $6 \mathrm{~g}$, respectivamente, e ilustram as tendências do processo de alteração descritas a seguir.
A figura 6 ilustra que a rocha é muito rica em $\mathrm{Mg}$ e este se perde, juntamente com o $\mathrm{Ca}$ e o $\mathrm{Si}$, de forma intensa nas primeiras fases de alteração, estando os alteromorfos iniciais com uma composição química similar à dos agregados de solo. O acúmulo relativo de elementos menos móveis nos alteromorfos, como o $\mathrm{Al}$ e o $\mathrm{Fe}$, também é evidente e alguns minerais de $\mathrm{Fe}$ mais resistentes ao intemperismo (espinélios) aparecem tanto na rocha como nos alteromorfos e no solo. Esta tendência corrobora muitos estudos da geoquímica de alterações de rocha ultrabásica em ambientes tropicais, que é a de acumulação de $\mathrm{Fe}_{2} \mathrm{O}_{3}$
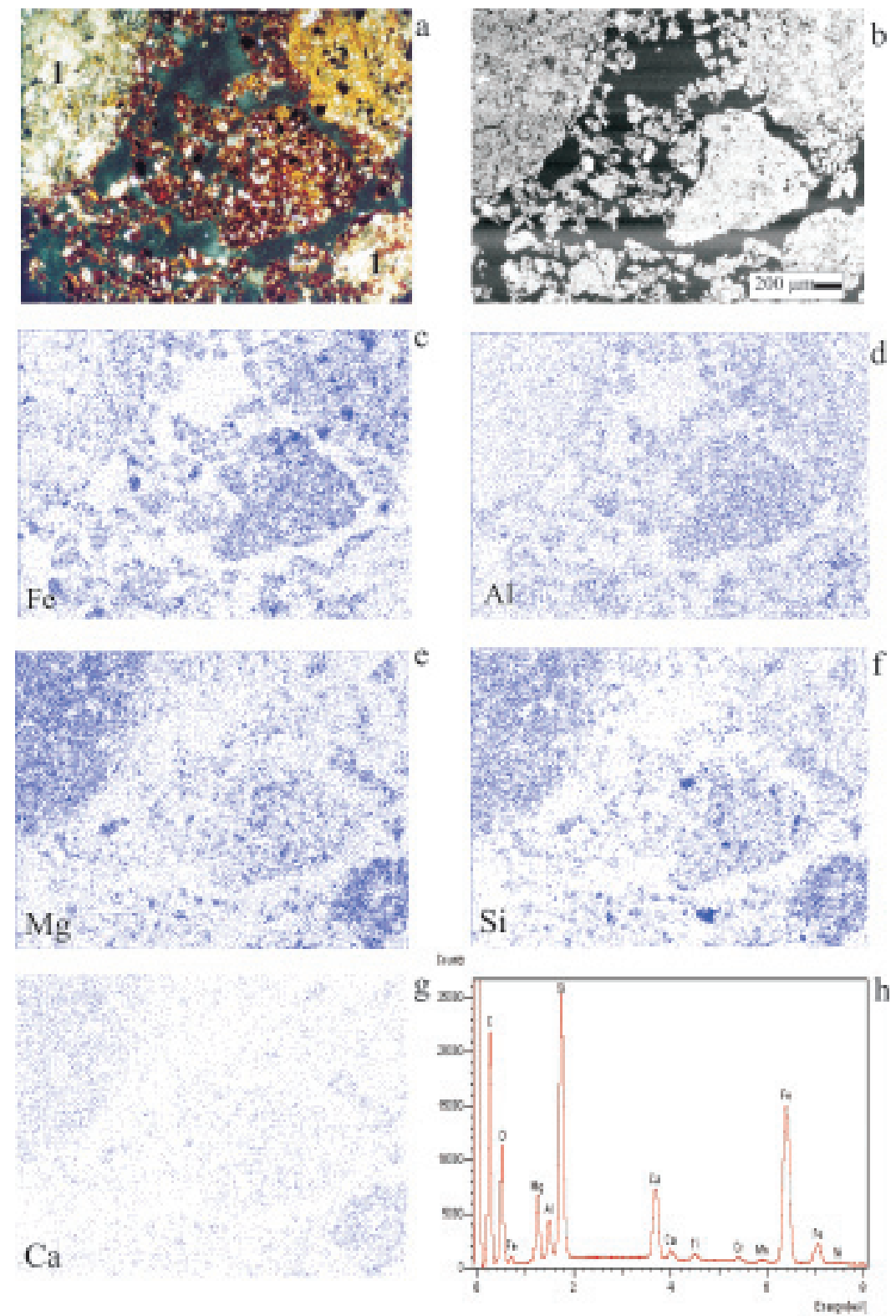

Figura 6. Análise química de uma seção delgada do horizonte Bi do perifl-1. (a): Fotomicrografia sob luz polarizada cruzada, ilustrando três fases distintas de alteração: rocha (1), alteromorfo (2) e agregado de solo ou ped (3). (b): Imagem de elétrons retroespalhados do mesmo campo da figura 8a. (c, d, e, f, g): imagens do mapeamento por EDRX feito para os elementos $\mathrm{Fe}, \mathrm{Al}, \mathrm{Mg}$, $\mathrm{Si}$, Ca respectivamente. (h): Espectro EDRX total do campo. 
e $\mathrm{Al}_{2} \mathrm{O}_{3}$ e a depleção em $\mathrm{Na}_{2} \mathrm{O}, \mathrm{K}_{2} \mathrm{O}, \mathrm{CaO}, \mathrm{MgO}$ em relação à rocha mãe (Trescases, 1975; Melfi et al., 1980; Menogotto, 1983; Akpanika et al., 1987). Na verdade, este modelo é bastante conhecido dos geoquímicos; contudo, procurou-se ilustrar nos volumes do solo como a alteração se procede em termos qualitativos.

A acumulação de óxidos de ferro no solum é evidente, com valores superiores a $200 \mathrm{~g} \mathrm{~kg}^{-1}$ na maioria dos horizontes $\mathrm{B}$ dos três perfis, como será visto adiante.

\section{Mineralogia dos solos}

Nos três perfis estudados, a composição mineralógica da fração argila apresenta uma mescla de: (a) minerais herdados, como o talco, a clorita e, em menor quantidade, a tremolita; (b) minerais de transformação direta, por rearranjamento estrutural, como os interestratificados clorita-vermiculita, cloritaesmectita, a vermiculita e a esmectita e (c) minerais neoformados por dissolução-precipitação, com destaque para a caulinita e para os óxidos de Fe (hematita e goethita) (Figura 7).

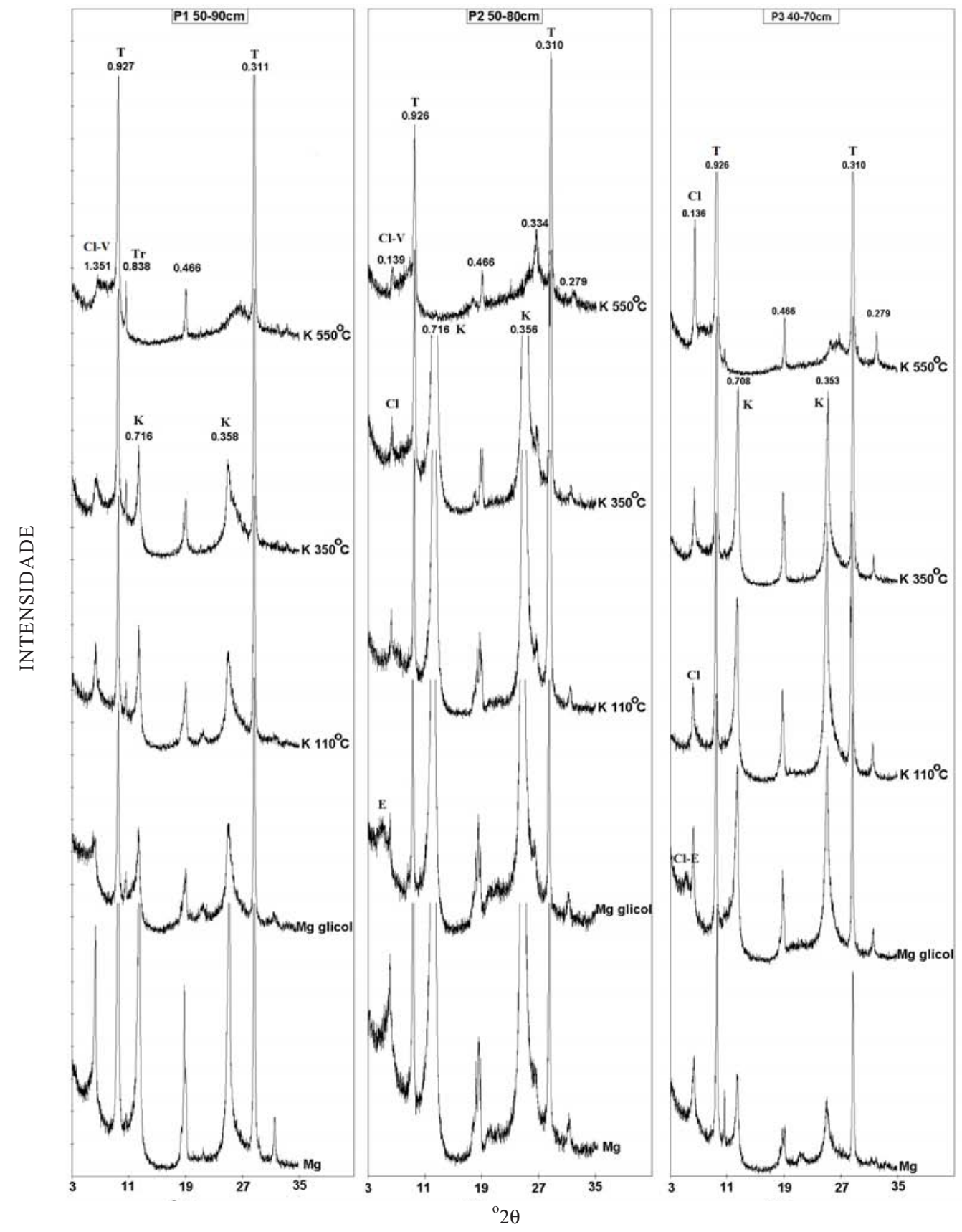

Figura 7. Difratogramas de raios X da fração argila dos horizontes Bi dos três perfis estudados. T:talco; Tr: tremolita; K:caulinita; Cl: clorita; E: esmectita; Cl-E:interestratificado clorita-esmectita; Cl-V: interestratificado clorita-vermiculita. 
Parte da caulinita poderia ser formada por mecanismos simultâneos de formação, envolvendo o rearranjamento estrutural e a dissolução-precipitação. Por esses mecanismos, em meios ácidos, folhas tetaedrais de Si seriam liberadas das cloritas e dos argilominerais 2:1 e se recombinariam com os hidróxidos de $\mathrm{Al}$ precipitados, formando, assim, um argilomineral 1:1 de origem mista. Esses mecanismos são considerados por Barnhisel \& Bertsch $(1988,1989)$ como alteração de argilominerais 2:1 em 1:1. Parte da caulinita porém, poderia ser formada a partir da solução do solo, por ser o mineral mais estável nas condições dominantes dos solos estudados, e não nos sistemas fissurais da alteração inicial com pH 9-10.

Além de distinção pelo pico basal de serpentina de $0,73 \mathrm{~nm}$ e o da caulinita $0,71 \mathrm{~nm}$, White \& Dixon (2002) indicam como aceitável o procedimento de distinguir entre caulinita e serpentinas ricas em $\mathrm{Mg}$ ou em Fe, a partir da observação dos difratrogramas de raios $\mathrm{X}$ após o tratamento a $550{ }^{\circ} \mathrm{C}$. Minerais formados em temperaturas mais elevadas que a ambiente, as serpentinas magnesianas e ferríferas são estáveis nessa condição, ao contrário da caulinita, que perde os picos basais a essa temperatura. Os autores chamam ainda a atenção para o fato de que as serpentinas ferríferas sofrem, na verdade, uma pequena redução de dimensões da cela unitária após a oxidação a $300-400{ }^{\circ} \mathrm{C}$ e que mantém estável sem que ocorra o colapso da estrutura acima de $500{ }^{\circ} \mathrm{C}$.

A caulinita foi identificada nos três solos estudados, com maior ocorrência no perfil 2, provavelmente pela presença de aluminossilicatos primários (feldspatos e micas), oriundos dos granitos encaixantes e identificados nas frações mais grosseiras desse solo pelo exame micromorfológico e na fração silte por DRX (Quadro 3).

Embora não determinado por DRX, uma vez que se trabalhou com amostras desferrificadas, a cor bruna, ou bruno amarelada, das fases mais próximas das alteritas nos perfis indica a presença da goethita, enquanto a cor vermelha dos horizontes mais pedogeneizados relaciona-se com a presença de hematita. Estes minerais são neoformados, mas parte do talco identificado pode ser também formada num ambiente pedogenético durante as fases iniciais de alteração (sistemas fissurais), nas quais se formariam soluções de $\mathrm{pH}$ muito elevado, entre 9 e10, valores estes similares aos do $\mathrm{pH}$ de abrasão da rocha sã, e com elevadas concentrações de Si e Mg. Provavelmente, uma associação talco-esmectita poderia ser a paragênese estável inicial nestes sistemas fissurais.

É importante ressaltar que, nesses solos, a ordem vertical dos horizontes não segue necessariamente a ordem de intemperismo, sendo a alteração mais intensa nas zonas de fraturamento ou de contato com outras rochas mais alteráveis, como é o caso do perfil 2 , que está na zona de contato entre o serpentinito e uma rocha granítica, sendo o horizonte $2 \mathrm{C}$ um saprolito branco e caulinítico bastante espesso, o que garantiria a drenagem e a maior velocidade de alteração do horizonte Bi em relação aos superpostos. Portanto, neste perfil, parte da caulinita pode ser de origem hidrotermal, por alteração do granito encaixante.

Quadro 3. Mineralogia da fração silte dos solos estudados, obtida por difração de raios X

\begin{tabular}{|c|c|c|}
\hline Horizonte & Profundidade & Mineralogia da fração silte \\
\hline \multicolumn{3}{|c|}{$\mathrm{cm}$} \\
\hline & & $\mathrm{P} 1$ \\
\hline $\mathrm{Al}$ & $0-10$ & $\operatorname{Tr}$ \\
\hline $\mathrm{A} 2$ & $10-30$ & $\mathrm{Tr}, \mathrm{Tc}$ \\
\hline $\mathrm{AB}$ & $30-50$ & $\mathrm{Tr}, \mathrm{Sp}, \mathrm{Tc}$ \\
\hline $\mathrm{Bi}_{1}$ & $50-90$ & Tr, Tc \\
\hline $\mathrm{Bi}_{2}$ & $90-110$ & $\mathrm{Tr}, \mathrm{Tc}$ \\
\hline $\mathrm{C}$ & $110-130$ & $\operatorname{Tr}, \mathrm{Tc}$ \\
\hline \multicolumn{2}{|l|}{$\operatorname{Rocha}^{(1)}$} & Tremolita, Clorita, Talco, Serpentina e opacos \\
\hline & & $\mathrm{P} 2$ \\
\hline $\mathrm{Bi}$ & $50-80$ & $\mathrm{Cl}, \mathrm{Tr}, \mathrm{M}, \mathrm{Sp}, \mathrm{Fd}, \mathrm{Tc}$ \\
\hline $\mathrm{B} / \mathrm{C}$ & $80-130$ & \\
\hline \multirow[t]{2}{*}{ Rocha(1) } & & Serpentina, Tremolita, Clorita e opacos \\
\hline & & P3 \\
\hline $\mathrm{AB}$ & $10-40$ & $\mathrm{Tr}, \mathrm{Tc}, \mathrm{C} 1, \mathrm{Sp}$ \\
\hline $\mathrm{Bi}$ & $40-70$ & $\mathrm{C} 1, \mathrm{Tr}, \mathrm{Sp}, \mathrm{Tc}$ \\
\hline $\operatorname{Rocha}^{(1)}$ & & Tremolita, serpentina, olivina serpentinizada, piroxenios, clorita, talco \\
\hline
\end{tabular}

Abreviações: Cl: clorita; V: vermiculita; Tr: Tremolita; Tc: Talco; Sp: serpentina; K: Caulinita; Fd: feldspato; M: mica.

(1) A mineralogia das rochas foi determinada pelo de exame ótico em seções delgadas. 
A clorita é identificada pela imobilidade que tem o pico de $1,4 \mathrm{~nm}$ ao término de todos os tratamentos. Isto foi verificado em todos os perfis, estando a clorita presente na fração argila dos três solos estudados. No entanto, o surgimento de uma banda de 1,4 a $1,8 \mathrm{~nm}$ nas amostras glicoladas dos três solos estudados indica a presença de esmectitas ou de interestratificado clorita-esmectita. Por outro lado, nos tratamentos térmicos, verificou-se o surgimento de uma banda entre o pico 1,4 e o de 1,0 nm após o tratamento térmico de $550{ }^{\circ} \mathrm{C}$, indicando o colapso de parte de um interestratificado com presença de vermiculita, provavelmente clorita-vermiculita (Figura 7).

A mineralogia da fração silte (Quadro 3) e, em especial, da fração da argila (Figura 7) confirma que os solos estudados são pouco intemperizados. A presença de tremolita dominando a fração silte da maioria dos solos e o fato de aparecer na fração argila dos perfis 1 e 3 , provavelmente associada à fração argila grossa, estão de acordo com o que foi encontrado por Pinto \& Kampf (1996) em solos derivados de rochas ultrabásicas com certo grau de serpentinização no ambiente subtropical do Rio Grande do Sul e considerados por estes autores como os de menor grau de intemperismo daquele estado.

Especial atenção deve ser dada à ocorrência do talco na fração argila dos três solos estudados. Identificados pelos seus picos basais e fundamentalmente o de $0,93 \mathrm{~nm}$ que é estável a $550{ }^{\circ} \mathrm{C}$ (Figura 7), uma vez que são raras as descrições deste mineral na fração argila de solos em ambientes tropicais úmidos. Segundo Zelazny et al. (2002), o talco se altera tipicamente para nontronita ou para óxido de $\mathrm{Fe}$ e, embora seja um mineral formado exclusivamente em ambiente não pedogenético, pode ter sua resistência ao intemperismo aumentada em ambiente com níveis elevados de $\mathrm{MgO}$, tal como Akpanika et al. (1987) verificaram em Ferralsol da Nigéria derivado de material similar aos destes solos (talcoxisto). Em meios enriquecidos em óxidos de Fe por alteração, o talco poderá persistir na fração argila, uma vez que poderá haver oclusão deste pelo revestimento oxídico (Pérez-Rodriguez et al., 1996).

A esmectita foi encontrada nos horizontes mais profundos de $\mathrm{P} 1$ e tanto pode ser formada a partir do talco como a partir da clorita. No entanto, não parece haver quantidades muito elevadas deste mineral puro nos três perfis, mas, sim, de seus interestratificados, o que evidencia que a alteração do talco pode estar relacionada com a formação de óxidos de $\mathrm{Fe}$, os quais ocorrem em quantidades elevadas nestes solos. A formação das esmectitas desses solos deve ser então proveniente da hidratação progressiva das folhas hidróxi das entrecamadas da clorita, com conseqüente perda de cátions, levando à formação de interestratificados clorita-esmectita numa etapa inicial. $\mathrm{O}$ mesmo raciocínio pode ser aplicado à gênese da vermiculita e dos interestratificados cloritavermiculita existente nesses solos, o que está de acordo com o trabalho de revisão bibliográfica realizado por
Kohut \& Warren (2002). Estes minerais também poderiam formar-se a partir de clorita ou de ferromagnesianos das fases finais de serpentinização, já que a formação dos grandes cristais de clorita e, ou, vermiculita, assim como de seus interestratificados, é muito freqüente em formações de rochas serpentinizadas (Pérez-Rodriguez et al., 1996; Robert \& Proctor, 1991).

Zelazny et al. (2002) apontam para o fato de que ocorrências anômalas de talco em solos têm aplicação na identificação de minérios ou de rochas ricas em talco que podem ser exploradas pela mineração.

\section{Atributos físicos, químicos e classificação dos solos}

Os três perfis derivados de serpentinitos apresentam um gradiente textural perceptível, sendo mais argiloso nos horizontes $\mathrm{B}$ ou $\mathrm{BC}$ do que nos horizontes C e A (Quadro 4). Esses gradientes podem mostrar a evolução para um Bt formado por argiluviação, processo constatado no exame micromorfológico. No entanto, é mais provável que seja resultado da ação conjunta da argiluviação e da erosão seletiva de finos (elutriação) nas camadas superficiais, com acúmulo de fragmentos grosseiros e da fração areia nos horizontes A, particularmente as frações areia grossa e areia muito grossa (Quadro 4). Embora tenha sido possível notar, no horizonte Bi de $\mathrm{P}-1$, alguma cerosidade no campo, o exame das lâminas delgadas indicou que a argiluviação está presente no horizonte Bi dos três perfis, o que se dá de forma localizada, sendo a relação textural B/A de 1,4, tanto em P-1 como em P-3, estando em P-2 um horizonte $\mathrm{C}$ interposto entre $\mathrm{A}$ e $\mathrm{B}$.

Os elevados conteúdos de silte e areia desses solos (ambos entre 250 a $400 \mathrm{~g} \mathrm{~kg}^{1}$ ) também indicam o baixo grau de intemperização. A elevada reserva mineralógica constatada deve-se ao fato de serem solos derivados de rochas constituídas essencialmente de minerais primários considerados decomponíveis (serpentina, tremolita, actinolita, clorita e talco).

Todos os solos são eutróficos, com Mg e Ca dominando o complexo de troca (Quadro 5). O desequilíbrio entre $\mathrm{Mg}$ e Ca esperados para estes solos (Graham et al., 1990; Roberts \& Proctor, 1991), com domínio do primeiro no complexo de troca, ocorre em quase todo o perfil 2 e no perfil 3, excetuando-se o horizonte orgânico superficial. No perfil 1, o Ca domina o complexo de troca nos horizontes superficiais, mas, a partir do horizonte $\mathrm{Bi} 2$, o Mg passa a predominar no complexo de troca. Certamente, o predomínio do $\mathrm{Mg}$ em relação ao $\mathrm{Ca}$, invertendo a ordem liotrópica natural que ocorre na maioria dos solos, deve-se à presença dos minerais intemperizáveis ricos em $\mathrm{Mg}$ que ocorrem em todas as frações estudadas, até mesmo na fração argila.

São solos com $\mathrm{pH}$ próximos da neutralidade e valores baixos a muitos baixos de $\mathrm{K}$ trocável e fósforo lábil. Nos horizontes $\mathrm{O}$ e $\mathrm{Al}$ do perfil 1, encontram-se valores 
relativamente altos de $\mathrm{P}$ lábil (30 $\mathrm{mg} \mathrm{kg}^{-1}$ ) para solos derivados de serpentinitos, o que está em desacordo com a bibliografia (Calvo de Anta et al., 1987). Contaminação eólica por apatitas e a própria ciclagem do fósforo pela vegetação são possíveis causas que poderiam explicar esses teores de $\mathrm{P}$ mais elevados.
A CTC/100 g de argila nos horizontes Bi dos três solos indica tratar-se de solos com argila de atividade alta (Embrapa, 1999) em P-1 e P-3 e média em P-2. Neste último perfil, o horizonte Bi apresenta valores relativos baixos de CTC, indicando a presença de argila de baixa atividade.

Quadro 4. Distribuição granulométrica das partículas

\begin{tabular}{|c|c|c|c|c|c|c|c|c|c|}
\hline \multirow{2}{*}{ Horizonte } & \multirow{2}{*}{ Profundidade } & \multicolumn{6}{|c|}{ Areia } & \multirow{2}{*}{ Silte } & \multirow{2}{*}{ Argila } \\
\hline & & Muito grossa & Grossa & Média & Fina & Muito fina & Total & & \\
\hline \multirow{2}{*}{\multicolumn{2}{|c|}{$\mathrm{cm}$}} & \multicolumn{8}{|c|}{$\mathrm{g} \mathrm{kg}^{-1}$} \\
\hline & & \multicolumn{8}{|c|}{ Perfil 1} \\
\hline 0 & -10 a 0 & 0 & 20 & 40 & 170 & 170 & 400 & 330 & 270 \\
\hline $\mathrm{Al}$ & $0-10$ & 10 & 30 & 40 & 120 & 170 & 370 & 400 & 230 \\
\hline $\mathrm{A} 2$ & $10-30$ & 50 & 40 & 30 & 90 & 100 & 310 & 350 & 340 \\
\hline $\mathrm{AB}$ & $30-50$ & 20 & 40 & 40 & 110 & 100 & 310 & 360 & 330 \\
\hline Bi 1 & $50-90$ & 10 & 20 & 20 & 70 & 110 & 210 & 380 & 400 \\
\hline $\mathrm{Bi} 2$ & $90-110$ & 0 & 10 & 10 & 50 & 70 & 140 & 280 & 580 \\
\hline \multirow[t]{2}{*}{$\mathrm{C}$} & $110-130$ & 10 & 20 & 20 & 10 & 170 & 320 & 230 & 450 \\
\hline & & \multicolumn{8}{|c|}{ Perfil 2} \\
\hline $\mathrm{O}$ & -5 a 0 & 20 & 60 & 80 & 160 & 110 & 430 & 240 & 330 \\
\hline $\mathrm{Al}$ & $0-10$ & 60 & 100 & 90 & 130 & 80 & 460 & 210 & 330 \\
\hline $\mathrm{CB}$ & $10-50$ & 10 & 20 & 30 & 90 & 100 & 250 & 290 & 460 \\
\hline $\mathrm{Bi}$ & $50-80$ & 10 & 20 & 20 & 70 & 90 & 210 & 290 & 500 \\
\hline \multirow[t]{2}{*}{$2 \mathrm{BC}$} & $80-130$ & 0 & 20 & 40 & 120 & 150 & 330 & 230 & 440 \\
\hline & & \multicolumn{8}{|c|}{ Perfil 3} \\
\hline $\mathrm{Ap}$ & $0-10$ & 30 & 80 & 80 & 110 & 90 & 390 & 320 & 290 \\
\hline Bil & $10-40$ & 20 & 40 & 40 & 90 & 90 & 280 & 320 & 400 \\
\hline $\mathrm{Bi} 2$ & $40-70$ & 0 & 0 & 10 & 90 & 150 & 250 & 320 & 430 \\
\hline
\end{tabular}

Quadro 5. Cor e atributos químicos dos horizontes dos solos

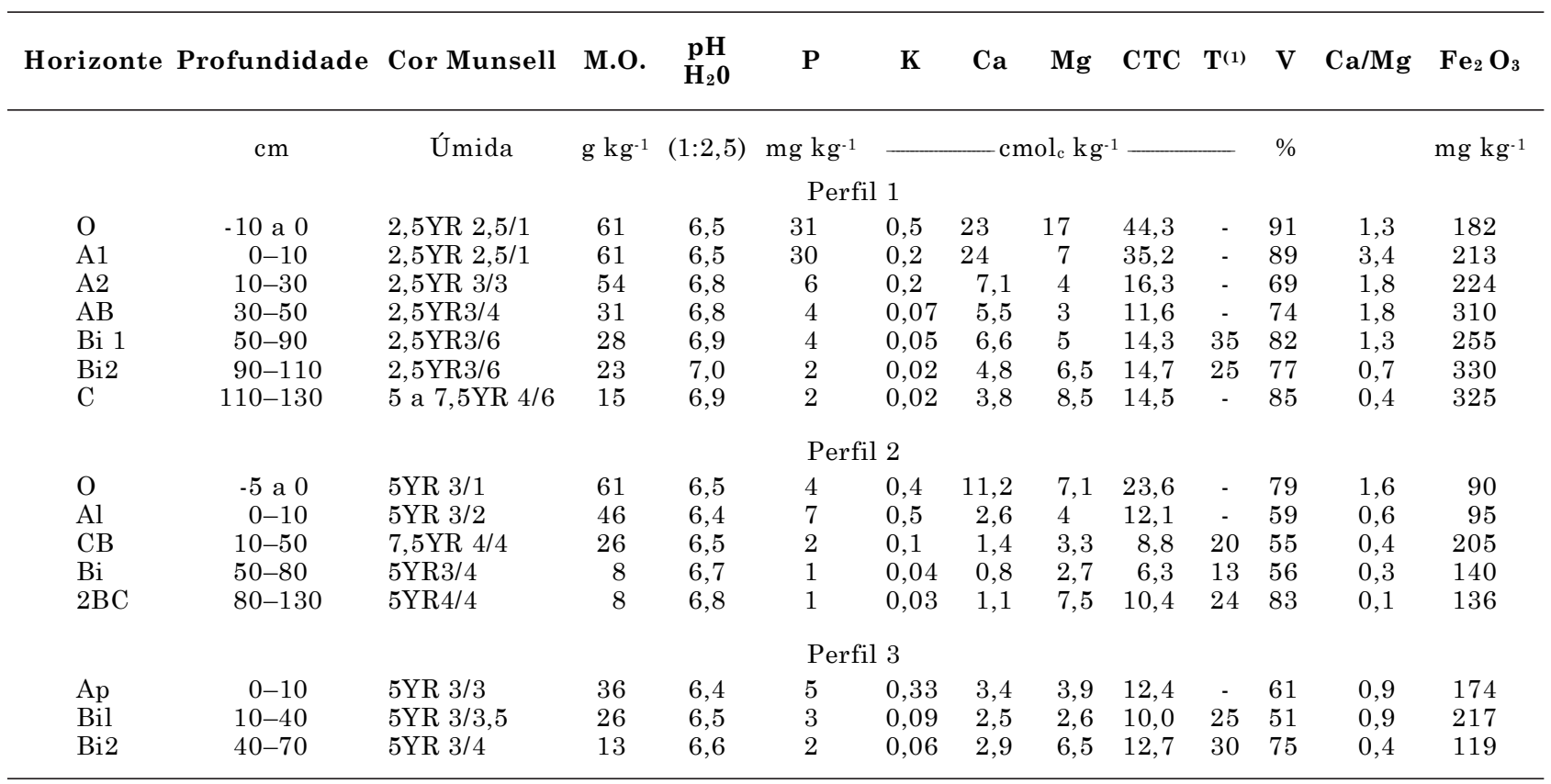

(1) CTC/100 g de argila determinado somente para o horizonte B para fins de classificação (Embrapa, 1999). 
Quadro 6. Classificação dos solos estudados, de acordo com o Sistema Brasileiro, antigo e atual, e Sistemas da FAO e do USDA

\begin{tabular}{llll}
\hline \multicolumn{1}{c}{ Perfil 1 } & \multicolumn{1}{c}{ Perfil 2 } & \multicolumn{1}{c}{ Perfil 3 } & Sistema de classificação \\
\hline Brunizem & Regossolo Eutrófico & Cambissolo Eutrófico & Camargo et al. (1987) \\
Chernossolo Háplico & Neossolo Regolítico & Cambissolo Háplico & Embrapa (1999) \\
Férrico típico & Eutrófico típico & Eutroférrico léptico & Soil Taxonomy (1999) \\
Typic Hapludoll & Typic Troporthent & Typic Eutropept & FAO (1988) \\
Haplic Phaeozem & Eutric Regosol & Chromic Cambisol & \\
\hline
\end{tabular}

Levando em conta a morfologia e os dados analíticos já comentados, além dos teores de $\mathrm{Fe}_{2} \mathrm{O}_{3}$ obtidos para os três solos estudados, estes foram classificados de acordo com a classificação brasileira antiga (Camargo et al., 1987), segundo o novo Sistema Brasileiro de Classificação de Solos (Embrapa, 1999) e segundo os sistemas internacionais de legenda da WRB-FAO (1988) e do Soil Taxonomy (USDA, 1999) (Quadro 6).

A seqüência não-usual de horizontes A-CB-Bi-2CR do perfil 2 causou certos problemas para enquadrá-lo nos sistemas de classificação considerados, tendo prevalecido a seqüência vertical A-C para classificá-lo nos diferentes sistemas.

\section{CONCLUSÕES}

1. No ambiente tropical úmido do sudeste de Minas Gerais, em superfícies geomórficas jovens, os solos desenvolvidos sobre rochas serpentinizadas são similares, ainda que com maior evolução mineralógica e geoquímica, aos seus correspondentes das regiões subtropicais e temperada do planeta.

2. No processo de formação de solo, a evolução da trama segue a seguinte seqüência: alterita $\rightarrow$ trama frâgmica $\rightarrow$ trama porfírica $\rightarrow$ trama porfírica com cavidades $\rightarrow$ trama porfírica aberta por coalescência de cavidades.

3. O processo de argiluviação é evidente e se dá em dois estádios distintos: nas fendas e cavidades que se formam por alteração da rocha (argiluviação primária) e na porosidade evoluída da coalescência das cavidades (argiluviação secundária). A tendência de evolução é para $\mathrm{B}$ textural com mineralogia 1:1 e alto conteúdo de óxidos de Fe.

4. Nas fases iniciais de alteração, os alteromorfos já apresentam composição química similar aos agregados do solo, com forte perda de $\mathrm{Mg}$, Ca e $\mathrm{Si}$ e acúmulo relativo de $\mathrm{Al}$ e $\mathrm{Fe}$.

5. Nos três perfis estudados, ocorre rejuvenescimento superficial por erosão diferencial, acumulando material grosseiro e removendo os finos, contribuindo para o incremento de relação textural.
6. A presença de minerais ricos em $\mathrm{Mg}$ nas diferentes frações, inclusive na fração argila, onde estão protegidos ou oclusos pelos óxidos de Fe, mantém um fornecimento deste elemento, o que garante relações $\mathrm{Ca} / \mathrm{Mg}$ baixas no complexo de troca, principalmente em subsuperfície.

\section{AGRADECIMENTOS}

À FAPESP e à Universidade de Santiago de Compostela, pelo suporte financeiro. Ao professor Antenor Zanardo da UNESP-Rio Claro, pela colaboração nas descrições petrográficas das rochas.

\section{LITERATURA CITADA}

ADAMSON, D.A.; SELKIRK, J.M. \& SEPPELT, R.D. Serpentine, harzburgite and vegetation on subantartic Macquarie Island. Artic Res., 25:216-219,1993.

AKPANIKA, O.I.; UKPONG, E.E. \& OLADE, M.A. Mineralogy and geochemical dispersion in tropical residual soils overlying a talc deposit in southwestern Nigeria. Chem. Geol., 63:109-119, 1987.

ALEXANDER, E.B.; WILDMAN, W.E. \& LYNN, W.C. Ultramafic (serpentinic) mineralogy class. In: KITTRICK, J.A., ed. Mineral classification of soils. Madison, Soil Science Society of America, 1985. p.135-146. (Special. Publication, 16)

ALEXANDER, E.B.; WILDMAN, W.E. \& LYNN, W.C. Ultramafic (serpentinic) mineralogy class. In: KITTRICK, J.A., ed. Mineral classification of productive soil on serpentinized peridotite in California (USA) Geoderma, 41:337-351, 1988.

BARNHISEL, R.I. \& BERTSCH, P.M. Chlorites and hydroxiinterlayered vermiculite and smectite. In: DIXON, J.B. \& WEED, S.B., eds. Minerals in soil invironments. 2.ed. Madison, Soil Science Society of America, 1989. p.726788. (Books Series, 1) 
BEINROTH, F.H. Some highly weathered soils of Puerto Rico, 1. Morphology, formation and classification. Geoderma, 27:1-73, 1982 .

BONIFÁCIO, E.; ZANINI, E.; BOERO,V. \& FRANCHINIANGELA, M. Pedogenesis in a soil catena on serpentinite in north-western Italy. Geoderma, 75:33-51, 1997.

BREWER, R. Fabric and mineral analysis of soil. New York, Rober E. Krieger Publishing, 1976. 482p.

BULMER, C.E.; LAVKUBICH, L.M. \& SCHREIER, H.E. Morphology, chemistry and mineralogy of soils derived from serpentine and tephra in southwestern Bristish Columbia. Soil Sci., 154:72-82, 1992.

CALVO DE ANTA, R.; MACÍAS, F. \& BUURMAN, P. Procesos de alteración y neoformación mineral en medios serpentínicos de Galicia. Cuad. Lab. Xeolóxico de Laxe, 11:161-170, 1987.

CAMARGO, M.N.; KLAMT, E. \& KAUFTMAN, J.H. Classificação de solos usada em levantamento pedológicos no Brasil. B. Inf. SBCS, 12:11-33, 1987.

CAMARGO, O.A.; MONIZ, A.C.; JORGE, J.A. \& VALADARES, J.M.A.S. Métodos de análise química, mineralógica e física de solos do Instituto Agronômico. Campinas, Instituto Agronômico, 1986. 94p.

CARVALHO, S.G.; SOARES, P.C.; ANTONIO, M.C.; ZARNADO, A. \& OLIVEIRA, M.A.F. Geologia da seqüência vulcano-sedimentar de Alpinópolis (MG). R. Bras. Geoc., 23:38-51, 1993.

CASTRO, S.S.; COOPER, M.; SANTOS, M.C. \& VIDALTORRADO, P. Micromorfologia do solo: bases e aplicações. In: CURI, N.; MARQUES, J.J.; GUILHERME, L.R.G.; LIMA, J.M.; LOPES, A.S. \& ALVAREZ V., V.H., eds. Tópicos em ciência do solo. Viçosa, MG, Sociedade Brasileira de Ciência do Solo, 2003. v.3. p.108-164.

COLEMAN, R.G. \& JOVE, C. Geological origin of serpentines. In: BAKER, A.J.M.; PROCTOR, J. \& REEVES, R.D., eds. The vegetation of Utramafic (Serpentine) Soils. In: INTERNATIONAL CONFERENCE ON SERPENTINE ECOLOGY, 1., Davis, 1991. Preceeding. Hampshire, Intercept, Hampshire, 1991. p.1-17.

EMPRESA BRASILEIRA DE PESQUISA AGROPECUÁRIA EMBRAPA. Centro Nacional de Pesquisa de Solos. Sistema brasileiro de classificação de solos. Brasília, 1999. $412 \mathrm{p}$.

ESCHENBRENNER, V. Contribution des termites á la microagrégation des sols tropicaux. Cahiers ORSTOM, Sér. Pédol., 22:397-408, 1986.

FAO-Unesco. Soil map of the world. Revised legend. Rome, 1988. 138p (World Soil Resources Report, 60)

GRAHAM, R.C.; DIALLO, M.M. \& LUND, L.J. Soils and mineral weathering on phyllite coluvium and serpentinite in Nortweastern California. Soil Sci. Soc. Am. J., 54:1682$1690,1990$.

JACKSON, M.L. Soil chemical analysis. Advanced course. Madison, Edição do autor, 1969. 894p.
KOHUT, C.K. \& WARREN, C.J. Chlorites. In: DIXON, J.B. \& SCHULZE, D.G., eds. Soil mineralogy with environmental application. Madison, Soil Science Society of America, 2002. p.531-553. (SSSA Books Series, 7)

LEMOS, R.C. \& SANTOS, R.D. Manual de descrição de coleta de solo no campo. 3.ed. Campinas, Sociedade Brasileira de Ciência do Solo, 1996. 83p.

MALPAS, J. Serpentine and the geology of serpentinized rocks. In: ROBERTS, B.A. \& PROCTOR, J., eds. The ecology areas with sepentinized rocks. A world view. Dordrecht, Kluwer Academic, 1991 p.7-30.

MELFI, A.J.; TRESCASES, J.J. \& OLIVEIRA, S.M.B. Les "laterites" nickeliferes du Brésil. Cah Orstom, Sér. Geol., 11:15-42, 1980.

MENEGGOTO, E. Intemperização de rochas ultrabásicas no Rio Grande do Sul, Brasil. R. Bras. Geociências, 13:178189, 1983.

MIKLÓs, A.A.W. Byodinamique d'une couverture pedologique dans la région de Botucatu, Nrésil. Paris, Université Paris VI, 1992. 2v. 438p. (Tese de Doutorado)

OLIVEIRA, S.M.B. Os depósitos de nível laterítico do Brasil. São Paulo, Universidade de São Paulo, 1990, 89p. (Tese de Livre Docência)

OLIVEIRA, S.M.B. \& TRESCASES J.J. Geoquímica da altração supérgena das rochsas ultramáficas de Santa Fé (Goiás, Brasil). R. Bras. Geoc., 10:244-257, 1980.

PÉREZ-RODRIGUEZ, J.L.; MAQUEDA, C.; RODRIGUEZRÚBIO, P. \& JIMENEZ DE HARO, M.C. Occurence of talc in soils with high iron content from the south-west of Spain. Autr. J. Soil Res., 34:635-651, 1996.

PINTO, L.F.S. \& KÄMPF, N. Solos derivados de rochas ultrabásicas no ambiente subtropical do Rio Grande do Sul. R. Bras. Ci. Solo, 20:447-458, 1996.

PROCTOR, J. \& WOODELL, S.R.J. The ecology of serpentine soils. Adv. Ecol. Res., 9:255-366, 1978.

RABENHORST, M.C.; FOSS, J.E. \& FANNING, D.S. Genesis of Maryland soils formed from Serpentinite. Soil Sci. Soc Am. J., 46:607-616, 1982.

RAIJ, B. van; QUAGGIO, J.A.; CANTARELLA, H.; FERREIRA, M.E., LOPES, A.S. \& BATAGLIA, O.A. Análise química do solo para fins de fertilidade. Campinas, Fundação Cargill, 1987. 165p.

ROBERTS, B.A. \& PROCTOR, J. The ecology of areas with serpentinized rocks. A world view. Dordrecht, Kluwer Academec, 1991. p.7-30.

SEGALEN, P.; BOSCH, D.; CARDENAS, A.; CAMACHO, E.; BOLEAU, A.; GUENIN, H. \& RAMBAUD, D. Aspects mineralogíques et pédogenétiques de deux sols derives de péridotites dans l'ouest de Cuba. Cah. ORSTOM, Sér. Pédol., 18:273-284, 1980.

STOOPS, G. \& JONGERIUS, A. Proposal for a micromorphological classification of soil materials. I. A classification of the related distribuion of fine and coarse particles. Geoderma, 13:189-199, 1975. 
TRESCASES, J.J. L'évolution géochimique supergéne des roches ultrabasiques en zone tropicale. Formation des gîsements nickelifères de Nouvelle-Caledonie. Nancy, 1975. 259p. (Men. ORSTOM, 78)

UNITED STATES DEPARTMENT OF AGRICULTURE USDA. National resources Conservation Service. Soil taxonomy. a basic system of soil classification for making and interpreting soil surveys. 2.ed. Washington, 1999.

VIDAL-TORRADO, P. Pedogênese e geoquímica de metais pesados em solos derivados de rochas serpentinizadas no sudoeste de Minas Gerais. Piracicaba, Escola Superior de Agricultura "Luiz de Queiroz", 1999. 109p. (Tese de Livre Docência)
VIDAL-TORRADO, P.; LEPSCH, I.F.; CASTRO, S.S. \& COOPER, M. Pedogênese em uma seqüência LatossoloPodzólico no bordo de um platô na depressão periférica paulista. R. Bras. Ci. Solo, 23:909-921, 1999.

WHITE, G.N. \& DIXON, J.B. Kaolin-Serpentine minerals. In: DIXON J.B. \& SCHULZE, D.G., eds. Soil mineralogy with environmental applications. Madison, Soil Science Society of America, 2002. p.389-414. (SSSA Books Series, 7)

ZELAZNY, L.W.; THOMAS, P.J. \& LAWRENCE, C.L. Pyrophilite-talc minerals. In: DIXON J.B. \& SCHULZE, D.G., eds. Soil mineralogy with environmental applications. Madison, Soil Science Society of America, 2002. p.415-430. (SSSA Books Series, 7) 